\title{
Investigation of the initiation mechanism of an earthquake- induced landslide during rainfall: a case study of the Tandikat landslide, West Sumatra, Indonesia
}

\author{
Fikri Faris ${ }^{*}$ and Wang Fawu
}

\begin{abstract}
Background: A large earthquake struck Padang Province, West Sumatra, Indonesia, at 17:16 on September 30, 2009. The earthquake had a moment magnitude of Mw 7.6, and triggered landslides in Tandikat, Padang Pariaman Regency. The landslides occurred during rainfall, and originated on mountains mantled with loose pumice, taking many lives. The unfortunate combination of intensive rainfall and strong earthquake probably decreased slope stability. This study seeks to examine the initiation mechanism of earthquake- induced landslides during rainfall, and to develop a new approach to predict pore pressure increase by assuming reciprocal relationships between strain, stiffness, and pore pressure.
\end{abstract}

Results: In order to assess slope stability, the concept of stiffness degradation was used to predict pore pressure increase due to earthquake. This was achieved by developing empirical formulation based on cyclic triaxial test results. A new procedure based on the "rigid block on quasi plastic layer" assumption was developed to assess slope stability of earthquake-induced landslides during heavy rainfall. Results from cyclic triaxial test experiments showed that effective confining pressure and initial shear stress had considerable influence on increase in pore pressure. Slope stability analysis using actual earthquake acceleration suggest that landslide occurred due to pore pressure build up and the factor of safety decreased rapidly before earthquake acceleration reached its peak.

Conclusions: The results emphasize the high risk of catastrophic earthquake-triggered landslides in tropical regions with high rainfall. It also suggest that landslide with similar mechanism of pore pressure increase are likely to occur on saturated sliding zones during smaller earthquakes.

Keywords: Earthquake induced landslide; Rainfall; Pore pressure increase; Pumice sand; Cyclic triaxial test; Indonesia

\section{Background}

One of the most devastating earthquakes in Indonesian history struck Padang, West Sumatra Province at 17:16 on September 30, 2009. The earthquake had a moment magnitude of $M_{w} 7.6$ (M7.6 2009.9.30), and caused over 1,000 deaths (EERI 2009). The M7.6 2009.9.30 Padang earthquake triggered many landslides, and these accounted for more than $60 \%$ of the total death toll. The most extensive landslides occurred in Tandikat, Padang Pariaman Regency. These buried hundreds of people, and flattened some villages (Figure 1). A loose pumice ash layer on the mountains is thought to have been saturated by extensive and heavy rainfall before the earthquake triggered the landslides. In this particular area, the probability of concurrent earthquake and rainfall events is high, since it has a tropical rainforest climate, and is also situated on a seismically active plate margin. Consequently, it is essential to study the initiation mechanisms of landslides of saturated pumice sand, while considering the effects of the unfortunate combination of independent events such as heavy rainfalls and earthquakes.

\footnotetext{
* Correspondence: fikri.faris.ugm@gmail.com

Department of Geoscience, Shimane University, Matsue 690-8504, Japan
} 


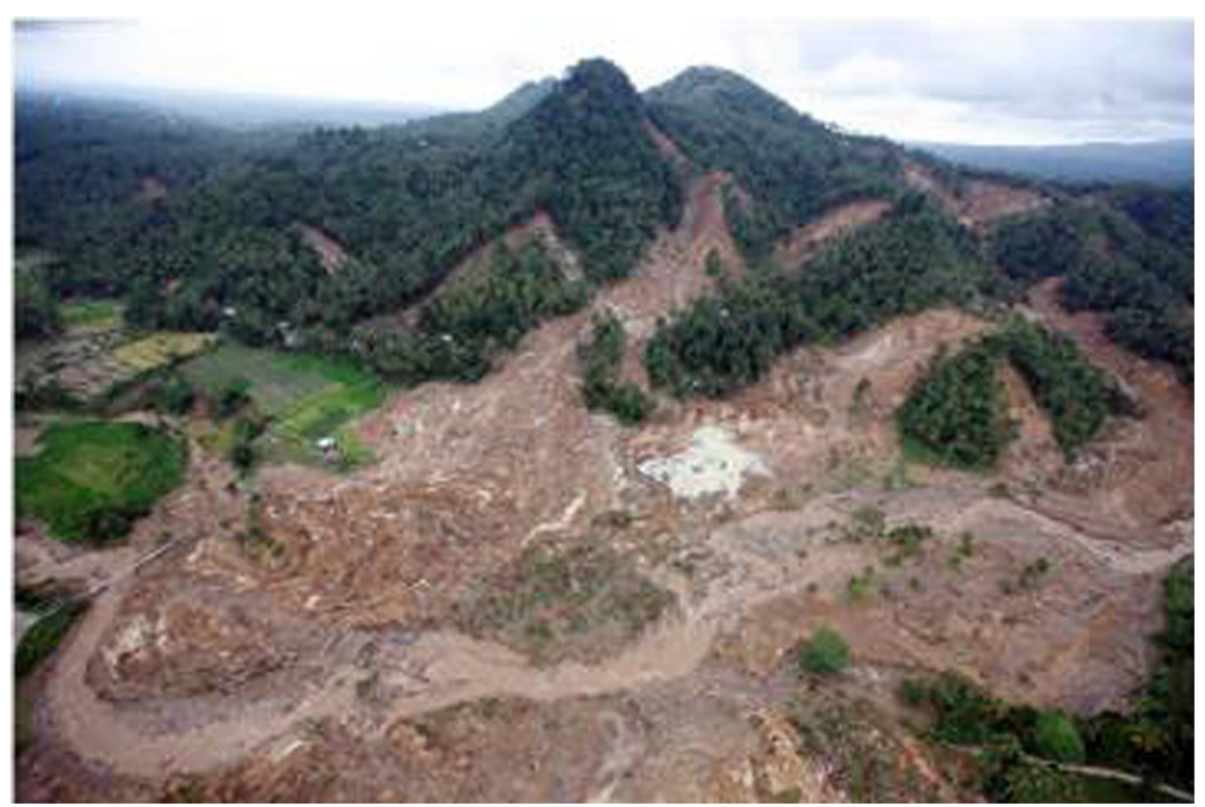

Figure 1 Widespread development of the Tandikat landslide (AP 2009).

Studies of initiation and post-failure mechanisms are conducted using different laboratory test methods. Studies of initiation mechanisms commonly use laboratory shearing tests considering "limited displacement" conditions (i.e. triaxial, hollow cylinder torsional shear, direct shear, and simple shear tests). Studies of post-failure mechanisms typically consider "large displacement" tests using ring shear tests.

The post-failure mechanism of volcanic deposits has been examined in several studies. A study of a long runout landslide in pyroclastic strata by Wang and Sassa (2000) used undrained ring shear apparatus to confirm grain crushing mechanism during shearing. Wang et al. (2010) also evaluated the post-failure mechanism of long run-out pumice material from the Tandikat landslide, using the same apparatus.

Several studies have examined the initiation mechanism of landslides in common volcanic soils, and the role of pore pressure build-up. Hyodd et al. (1998) examined the liquefaction characteristics of several crushable volcanic deposits, and Suzuki and Yamamoto (2004) emphasized the liquefaction characteristics of the Shirashu pyroclastic deposit in Japan, using cyclic triaxial tests on disturbed and undisturbed samples. However, specific research on the dynamic properties of pumice sand and its relation to pore pressure generation is rare.

Researches based on pore pressure models mainly use regular sand for laboratory tests, with very limited effort focused on the dynamic behaviour of volcanic sand, especially pumice sand. Seed et al. (1976) and Lee and Albaisa (1974) used clean sand to study liquefaction, and to develop a pore pressure model based on the number of cyclic loads. Yamazaki et al. (1985), Sugano and Yanagisawa (1992) and Jafarian et al. (2012) used Toyoura silica sand to derived pore pressure models based on the strain energy concept, using a variety of laboratory tests. Work on the behaviour of pumice during dynamic load has been reported by Marks et al. (1998) and Orense and Pender (2013). These authors studied the liquefaction characteristics and resistance of crushable pumice soils from North Island, New Zealand, based on undrained cyclic triaxial tests and field test data. They confirmed that pore pressure built up during shearing. Nevertheless, an empirical model for pore pressure generation in such material has not yet been developed.

This study examines the initial mechanism of earthquakeinduced landslides during rainfall, by development of a pore pressure model using local pumice sand, and the use of a cyclic triaxial apparatus. The pore pressure model proposed is based on assumption of a reciprocal relationship between strain, stiffness, and pore pressure. This model was then incorporated with groundwater simulation and slope stability analysis to encompass the problem of earthquake-induced landslides during rainfall. To fulfil this purpose, field investigations and laboratory tests using a stress-controlled cyclic triaxial apparatus were conducted to examine the physical behaviour of pumice sand from the Tandikat landslide district.

\section{Study site}

\section{Geological setting}

The Tandikat landslides occurred in Nagari Tandikat, Padang Pariaman Regency, around $60 \mathrm{~km}$ NNW of Padang City, West Sumatra Province, near the western coast of 
Sumatra, Indonesia (Figure 2). This area experiences frequent high intensity earthquakes, due to the oblique movement of the Indo-Australia and Euro-Asian plates that formed the Sumatran Fault System. This also results in uplift of trench basement, which runs the length of the Barisan Mountains forming volcanic mountains parallel to the west coast (Aydan 2009).

The landslides are located in a mountainous area around two volcanoes (Mt. Tandikat and Mt. Singgalang), and are extensively distributed on steep slopes inclined at $\sim 30$ to 50 degrees. The slopes are mainly mantled by unconsolidated volcanic deposits that were derived from the nearby mountains. This topographical condition is considered to be an important contributory factor for landslides in Tandikat.

According to the Padang geological map (Petersen et al. 2007) in Figure 3, landslide distribution was concentrated on Quaternary volcanic bedrock, denoted as Qvf (Quaternary volcanic rocks along flank of volcanoes). The surface deposits consist of silts, sands, and gravels, with remnants of pumice-tuff. Particularly in this area, impermeable clay strata are overlain by a porous pumice sand layer. From observations of landslide scarps and outcrops, the pumice sand deposits are clearly distinguishable from the clay strata (Figure 4a). Measurements show the thickness of the pumice sand layers is generally about 2 to 3 meters. Low permeability of the clay stratum was confirmed from water ponding which was observed on the exposed sliding surface of the clay layer (Figure 4b).

\section{Seismicity and meteorology}

Several high magnitude earthquakes have been recorded in the subduction zone along the west coast of Sumatra in the last few decades. The $M_{w} 9.0$ Aceh earthquake of December 26, 2004 caused the catastrophic Indian Ocean tsunami. The Nias earthquake of March 28, 2005, and the South Sumatra earthquake of September 12, 2007, had magnitudes of $M_{w} 8.7$ and $M_{w} 8.4$, respectively. The most recent large earthquake was the September 30, 2009 Padang earthquake, which had a moment magnitude of 7.6. The epicenter was located offshore, WNW of Padang City, and the hypocenter was located at a depth of $80 \mathrm{~km}$, within the oceanic slab of the IndoAustralian plate. This earthquake has been interpreted as an indication of a higher possibility of an imminent mega-earthquake in this region (Aydan 2009).

One of the most damaged areas due to earthquakeinduced landslide was in Cumanak Village of Nagari Tandikat, Patamuan sub-district, Padang Pariaman regency, about $60 \mathrm{~km}$ from the epicenter. Based on rainfall data interpreted from X-band Doppler Radar of the HARIMAU project provided by the Japan Agency for Marine-Earth Science and Technology (JAMSTEC) at Padang Pariaman Regency, rainfall of moderate intensity began at about 12:30, some hours prior to the earthquake shock at 17:16 local time (Figure 5). Antecedent rainfall of medium intensity (about $50 \mathrm{~mm} / \mathrm{h}$ ) was recorded the previous night. It is suspected that this rainfall played a major role in the triggering of the landslide. The contribution of rainfall to earthquake-induced landslides is of great concern in the volcanic area surrounding the west coast of Sumatra, which has equatorial weather that usually brings rainfall of high intensity, even during dry season periods (Sipayung et al. 2007). Based on the latest meteorological research on west coast of Sumatra, high intensity rainfall is frequently

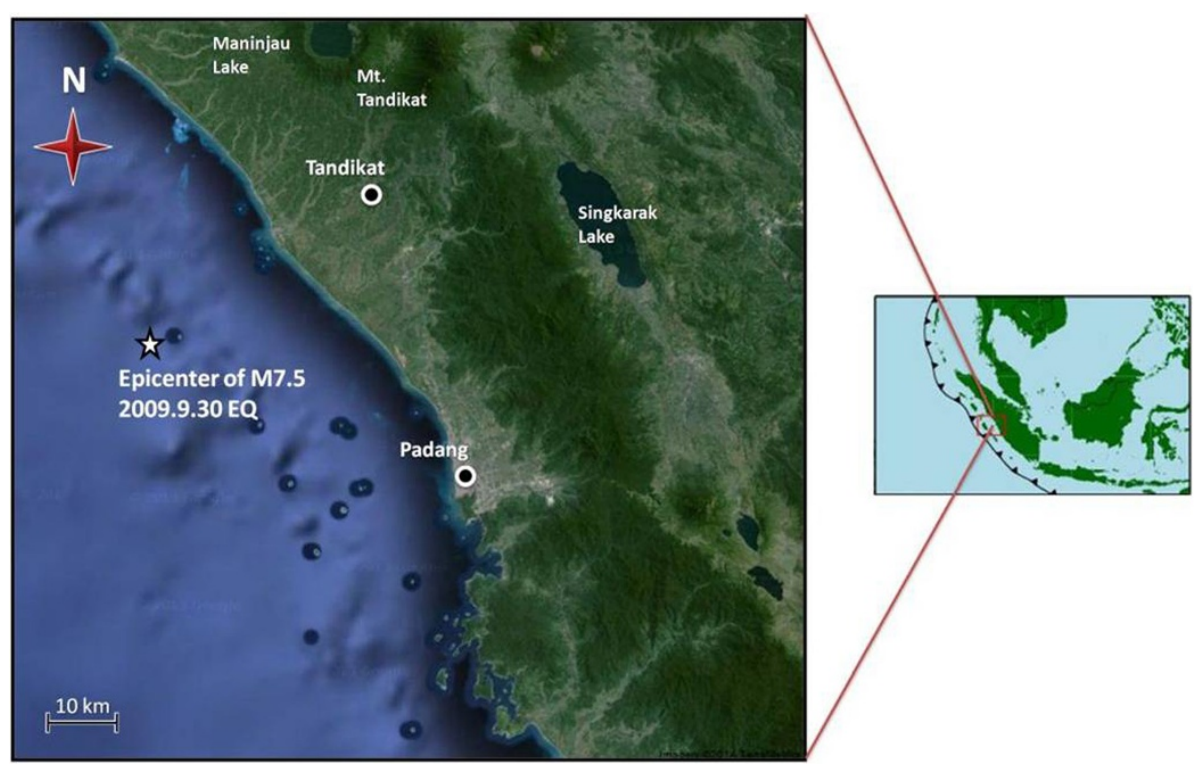

Figure 2 Location of the earthquake epicenter and landslide area (modified from Google Map 2014). 


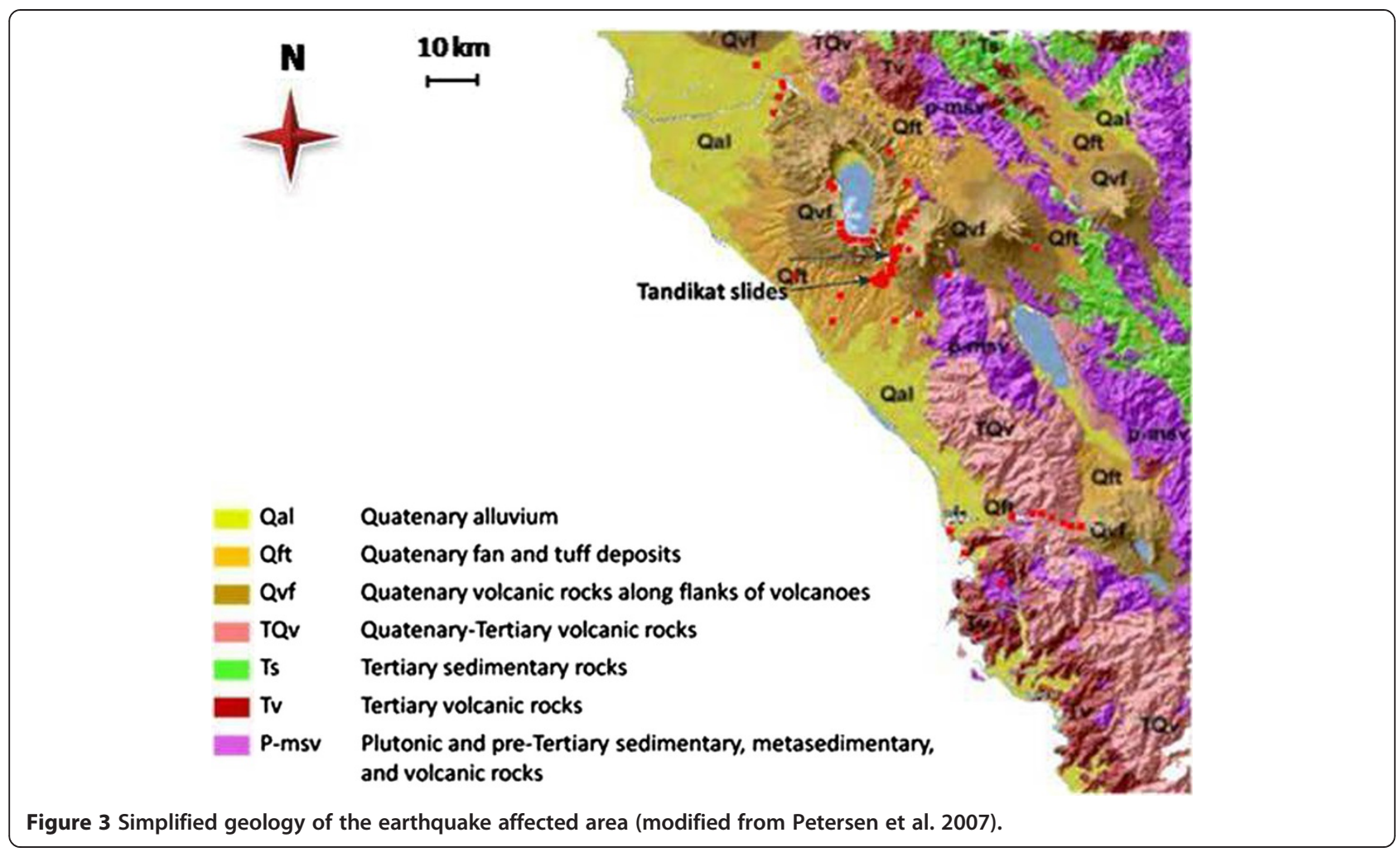

recorded in the late afternoon or evening, and distribution of such rainfall is strongly controlled by the mountainous topography of the area (Wu et al. 2009). The combined effects of seismic activity and meteorological conditions in this area create a high risk of failure of saturated volcanic deposits during earthquakes. These factors must be taken into consideration in geo-hazard assessment and mitigation.

\section{Methods}

Field investigation

Field investigations were conducted to understand the geological features in the area and the mechanism of the landslides. Methods included outcrop observations and soil sampling, and subsurface examination using boreholes and the Standard Penetration Test (SPT). Geological logging was also performed simultaneously with SPT at the same borehole. The interpretation of landslide stratigraphy based on geological logging is presented in Figure 6. The bedrock comprises moderately weathered medium- to fine-grained andesitic sandstones, which are overlain by stiff sandy clay, followed by unconsolidated tuffaceous pumice sand. The latter forms the main material of the landslide deposits.

The low density and high porosity of the pumice sand in its original state was confirmed by in-situ permeability
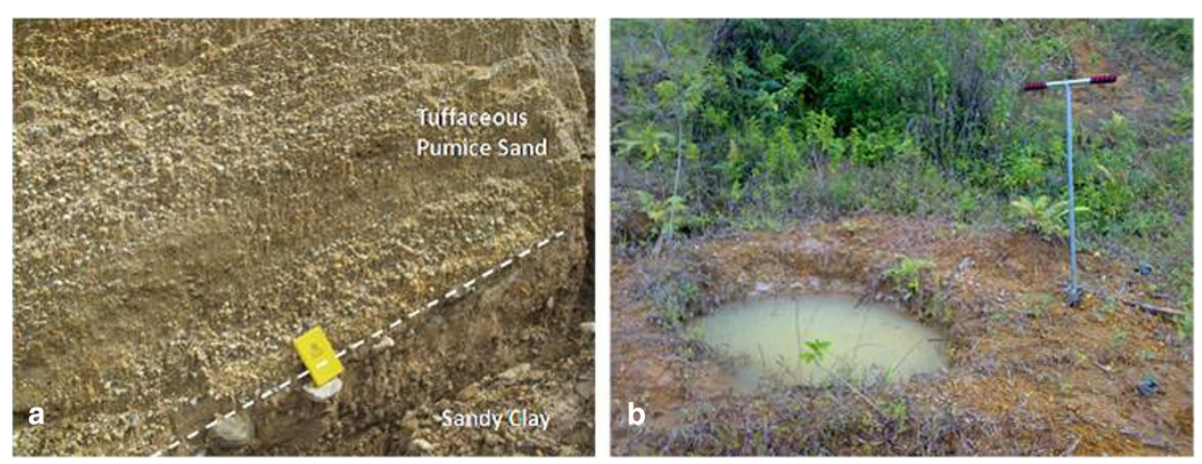

Figure 4 Stratigraphy of Tandikat landslide area (a) Outcrop showing the distinctive layer of sandy clay overlain by pumice sand (b) Water ponding on the sandy clay layer, illustrating the low permeability of this layer. 


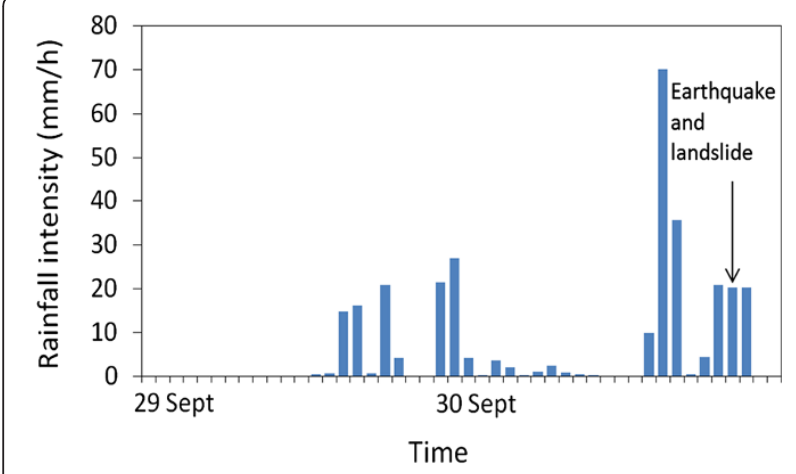

Figure $\mathbf{5}$ Rainfall record in $\mathbf{4 0}$ hours prior to the earthquake in the Tandikat region.

tests and density measurements. In-situ permeability was determined by the Phillip-Dunne permeameter method as a simple field technique for measuring saturated hydraulic conductivity $\left(k_{\mathrm{s}}\right)$ and Green-Ampts suction at the wetting front, $(\psi)$ (Muñoz-Carpena et al. 2002). This method was developed by Philip (1993) to estimate saturated hydraulic conductivity using Green-Ampt analysis approximation. The method reasonably satisfies the Green-Ampts model, which is used later in this study in assessing soil saturation due to rainfall infiltration. Falling head permeameter tests were conducted in the field using an open-ended pipe $0.085 \mathrm{~m}$ in diameter and $0.5 \mathrm{~m}$ in length. The ground surface around the sampling point was first cleared, and the end of the pipe was then penetrated $0.2 \mathrm{~m}$ into the soil. A volume of water was then poured into the permeameter pipe, and the change of water level was recorded at each time interval. In the original procedure of Phillip-Dunne permeameter, it is necessary to measure the infiltration times when permeameter is half full $\left(t_{\mathrm{med}}\right)$ and empty $\left(t_{\max }\right)$ (Regalado et al. 2005). In this study, the parameters $t_{\text {med }}$ and $t_{\text {max }}$ were estimated by linear regression of time vs. water level. The test was repeated several times at each site. The following equation of Regalado et al. (2005) was used to estimate saturated hydraulic conductivity $\left(k_{\mathrm{s}}\right)$ and the Green-Ampts suction at the wetting front $(\psi)$ :

$$
\begin{aligned}
& k_{\mathrm{s}}=\frac{\left(0.731 t_{\mathrm{max}} / t_{\mathrm{med}}-1.112\right) \pi^{2} r_{\mathrm{i}}}{8 t_{\max }} \\
& \log \psi=-13.503+19.678\left(t_{\max } / t_{\mathrm{med}}\right)^{-1 / 2}
\end{aligned}
$$

where $r_{\mathrm{i}}$ is the internal radius of the pipe.

Density measurement was conducted by inserting a plastic pipe into the soil. The pipe was then carefully pulled out of the ground, and the volume and weight of the soil inside was measured. The results of the in-situ falling head permeameter tests and density measurements are given in Table 1.

\section{Infiltration model}

Rainfall is thought to have contributed greatly to the landslide event. Some hours of rainfall infiltration before the earthquake may have saturated the slope. During this condition, seismic load probably generated excess pore pressure in the saturated soil, and this could dramatically decrease the slope stability. The commonly used GreenAmpt model (Green and Ampt 1911) for one dimensional rainfall infiltration was adopted to assess water infiltration and soil saturation during rainfall. The Green-Ampt model is a simple infiltration model which was derived from the rigorous Richard's equation, which assumes infiltration as a strict wetting front moving downward (Hsu et al. 2002). This model was originally used to assess water infiltration on horizontal ground surfaces. Chen and Young (2006) proposed modified Green-Ampt equations for sloping ground surfaces:

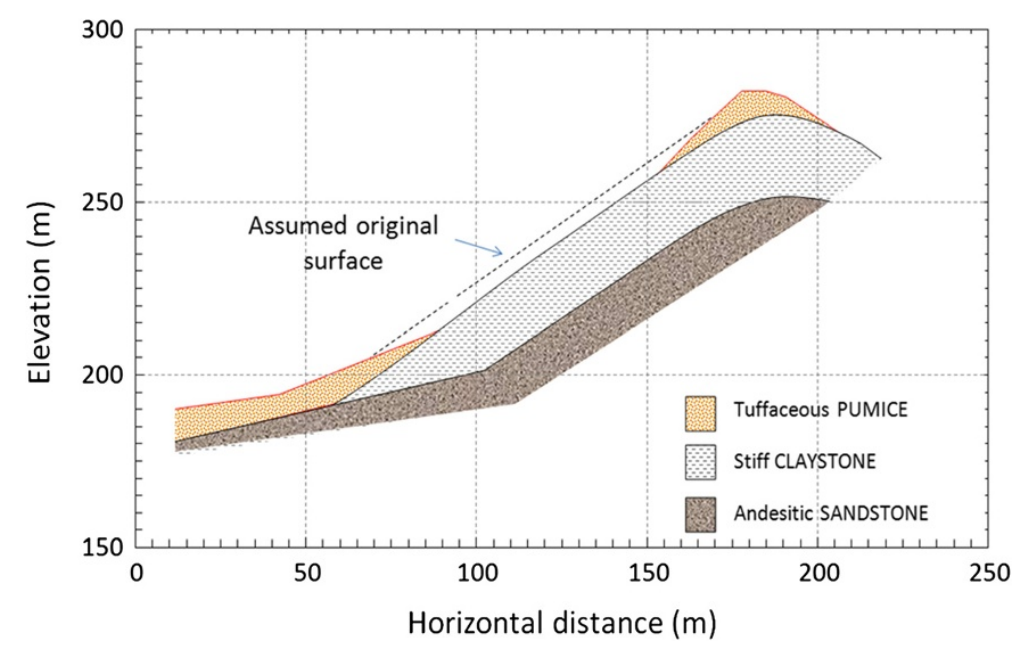

Figure 6 Interpretation of landslide stratigraphy based on geological logging (longitudinal section). 
Table 1 Input parameters used in the Green-Ampt infiltration model

\begin{tabular}{ll}
\hline Infiltration model parameters & Values \\
\hline Saturated hydraulic conductivity, $k_{\mathrm{s}}(\mathrm{mm} / \mathrm{h})$ & 300 \\
Suction head, $\psi(\mathrm{mm})$ & 240 \\
Initial volumetric water content, $\Delta w_{\mathrm{i}}$ & 0.62 \\
Volumetric water content at saturation, $\Delta w_{\mathrm{s}}$ & 0.71 \\
Slope angle, $\theta\left(^{\circ}\right)$ & 30 \\
\hline
\end{tabular}

$$
\begin{aligned}
& f(t)=k_{\mathrm{s}}\left[\cos \theta+\frac{(\psi \cdot \Delta w)}{F(t)}\right] \\
& F(t)-\frac{(\psi \cdot \Delta w)}{\cos \theta} \ln \left[1+\frac{F(t) \cos \theta}{(\psi \cdot \Delta w)}\right]=k_{\mathrm{s}} \cos \theta
\end{aligned}
$$

where $f(t)=$ potential infiltration rate at time $\mathrm{t}, F(t)=\mathrm{cu}$ mulative infiltration at time $t, \psi=$ suction head at the wetting front, $\Delta w=$ volumetric water content deficit, and $\theta=$ slope angle.

The result of the Green-Ampt infiltration analysis for the Tandikat area at about 40 hours before the earthquake is shown in Figure 7. The analysis used the parameters listed in Table 1 . The initial volumetric water content was determined from direct measurement of samples taken 24 hours after heavy rainfall during the field investigation. The result shows that the depth of the wet front $\left(z_{\mathrm{w}}\right)$ had already surpassed the three-metre depth where the impermeable sandy clay is located. This suggests that water percolated into the pumice sand during rainfall, and collided with the impermeable sandy clay layer. This generated a temporary perched groundwater table, which consequently created fully saturated conditions in the lower part of the pumice sand.

\section{Groundwater modelling}

Many researches have been conducted to develop numerical model to predict groundwater in unconfined aquifer. Among many methods, Boussinesq equation is most often used to estimate groundwater (Bansal and Das 2010). The performance of this method is reliable to predict experimental soil flume test (Steenhuis et al. 1999; Sloan and Moore 1984). This method generally formulated as a parabolic nonlinear equation, thus linearization process is used to derive analytical solution. Alternatively, finite difference numerical model can be used to utilize the aforesaid equation (Bansal 2013).

In this paper, Boussinesq equation was utilized in groundwater model to estimate temporary perched groundwater table generated by rainfall infiltration. The Boussinesq formula as the governing equation of the model is written as Eq. 5 (Bansal 2013). The illustration of the model is shown in Figure 8.

$$
k_{\mathrm{s}}\left\{\frac{\partial}{\partial x}\left(h \frac{\partial h}{\partial x}\right)-\tan \theta \frac{\partial h}{\partial x}\right\} \cos ^{2} \theta+R=S \frac{\partial h}{\partial t}
$$

where $h$ is the height of phreatic surface measured above the impermeable sloping bed in the vertical direction. $k_{\mathrm{s}}$ and $S$ respectively are the hydraulic conductivity and specific yield of the aquifer. $R$ is the net rate of recharge of infiltrated rainfall and $\theta$ is the bed slope.

The nonlinear Boussinesq equation can be solved numerically using the Mac Cormack scheme of explicit finite difference method (Bansal 2013). This can be done by modifying the Eq. 5 to Eq. 6 .

$$
\frac{\partial h}{\partial t}=C_{1} \frac{\partial}{\partial x}\left(h \frac{\partial h}{\partial x}\right)-C_{2} \frac{\partial h}{\partial x}+\frac{R}{S}
$$

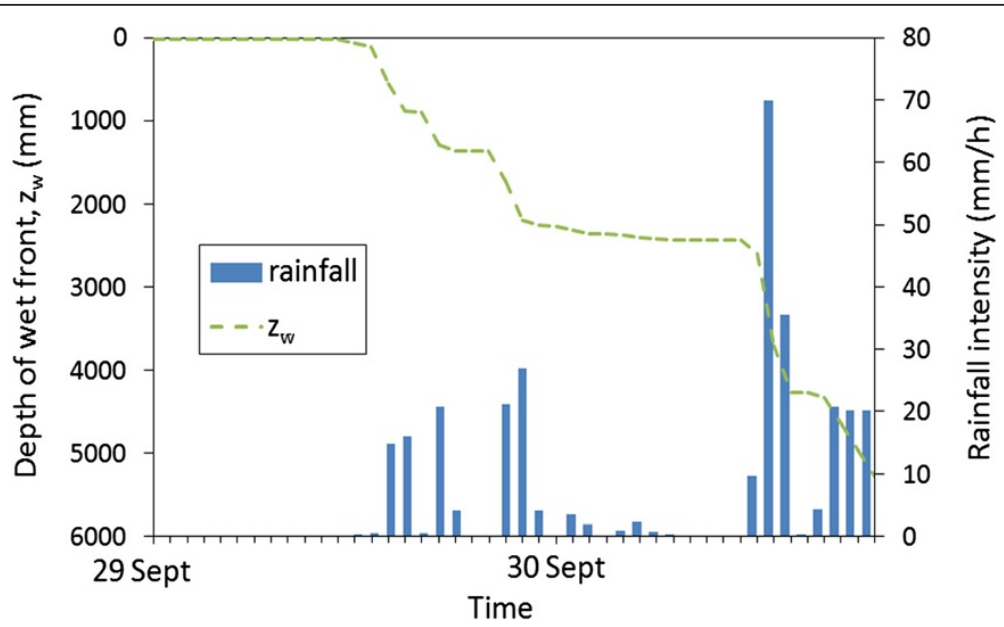

Figure 7 Infiltration analysis result showing depth of the wet front $\left(z_{w}\right)$ development during the 40 hours before the earthquake. 


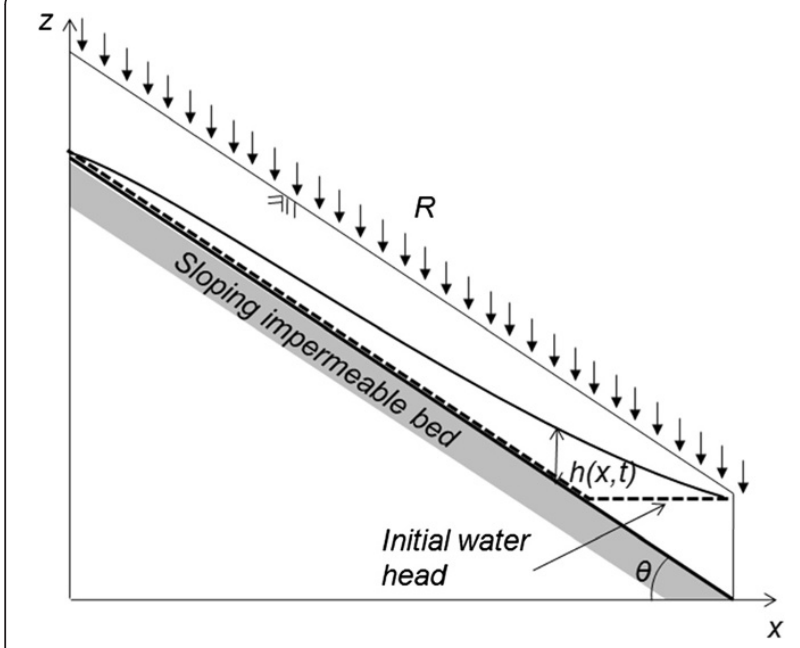

Figure 8 Scheme of groundwater model by rainfall infiltration.

where, $C_{1}=\left(k_{\mathrm{s}} \cos ^{2} \theta\right) / S$ and $C_{2}=\left(k_{\mathrm{s}} \sin 2 \theta\right) / 2 S$. Mac Cormack scheme is an explicit finite difference with predictor-corrector step. The predictor step is applied by replacing the spatial and temporal derivatives by forwards difference to obtain predicted value of $h$, indicated as $h^{\bullet}$ in Eq. 7.

$$
\begin{aligned}
h_{n, t+1}^{\cdot}= & h_{n, t}+C_{1} \frac{\Delta t}{(\Delta x)^{2}}\left[h_{n+1, t}\left(h_{n+1, t}-h_{n, t}\right)\right. \\
& \left.-h_{n, t}\left(h_{n, t}-h_{n-1, t}\right)\right]-C_{2} \frac{\Delta t}{\Delta x}\left(h_{n+1, t}-h_{n, t}\right)+\frac{R}{S} \Delta t
\end{aligned}
$$

where, subscript $n$ and $t$ are respectively spatial and time identifier, $\Delta x$ and $\Delta t$ are horizontal spatial interval and time interval, respectively. The corrector step is then obtained by replacing the space derivative by rearward difference, while the time derivative is preserved using forward difference approximation. Then Eq. 8 can be obtained.

$$
\begin{aligned}
h_{n, t+1}^{. .}= & h_{n, t}+C_{1} \frac{\Delta t}{(\Delta x)^{2}}\left[h_{n, t+1}^{\cdot}\left(h_{n+1, t+1}^{\cdot}-h_{n, t+1}^{\cdot}\right)\right. \\
& -h_{n-1, t+1}^{\cdot}\left(h_{n, t+1}^{\cdot}-h_{n-1, t+1}^{\cdot}\right) \\
& \left.-C_{2} \frac{\Delta t}{\Delta x}\left(h_{n, t+1}^{\cdot}-h_{n-1, t+1}^{\cdot}\right)+\frac{R}{S} \Delta t\right]
\end{aligned}
$$

The final value of $h_{n, t+1}$ is simply obtained from arithmetic mean of $h_{n, t+1}^{\cdot}$ and $h_{n, t+1}^{. \bullet}$ from Eqs. 7 and 8, respectively, and the Eq. 9 is obtained.

$$
\begin{aligned}
h_{n, t+1}= & \frac{1}{2}\left[h_{n, t}+h_{n, t+1}^{\cdot}-C_{2} \frac{\Delta t}{\Delta x}\left(h_{n, t+1}^{\cdot}-h_{n-1, t+1}^{\cdot}\right)\right. \\
& +C_{1} \frac{\Delta t}{(\Delta x)^{2}} \times\left\{h_{n, t+1}^{\cdot}\left(h_{n+1, t+1}^{\cdot}-h_{n, t+1}^{\cdot}\right)\right. \\
& \left.\left.-h_{n-1, t+1}^{\cdot}\left(h_{n, t+1}^{\cdot}-h_{n, t+1}^{\cdot}\right)\right\}\right]+\frac{R}{S} \Delta t
\end{aligned}
$$

The applied initial condition was used such as to simulate the water table condition in dry condition. Thus, the initial and boundary condition are defined by Eqs. 10, 11 and 12.

$$
\begin{aligned}
& h(x, t=0)=\left\{\begin{array}{cl}
0 & , x<L-x_{0} \\
z_{0}+(x-L) \tan \theta & , x>L-x_{0}
\end{array}\right. \\
& h(0, t)=0 \\
& h(L, t)=z_{0}
\end{aligned}
$$

\section{Laboratory tests}

Disturbed soil samples were taken from the pumice sand layer during field investigations to obtain their physical and mechanical properties. Physical properties such as specific gravity and grain-size distributions were obtained through specific gravity examination and grain-size distribution tests under ASTM D854-10 and ASTM D6913 procedures, respectively. Specific gravity and void ratio are shown in Table 2. High void ratio illustrates the loose structure of the pumice layer, and it is associated with the large and interconnected pores as observed during field investigation. The grain size distribution of a representative sample is presented in Figure 9. Based on the Unified Soil Classification System, this sample is classified as a well graded sand, which has a uniformity coefficient $\left(C_{\mathrm{u}}\right)$

Table 2 Pumice sand properties obtained from in-situ measurement and laboratory tests

\begin{tabular}{ll}
\hline Pumice sand properties & Values \\
\hline Specific gravity & 2.664 \\
Bulk density $\left(\mathrm{g} / \mathrm{cm}^{3}\right)$ & 1.503 \\
Dry density $\left(\mathrm{g} / \mathrm{cm}^{3}\right)$ & 0.888 \\
Relative density $(\%)$ & $\approx 50$ \\
Void ratio, e & 2.00 \\
Uniformity coefficient $\left(C_{\mathrm{u}}\right)$ & 8.19 \\
Coefficient of curvature $\left(C_{c}\right)$ & 1.03 \\
Saturated hydraulic conductivity, $k_{\mathrm{s}}(\mathrm{m} / \mathrm{s})$ & $4.42 \times 10^{-5}$ \\
Suction head, $\psi(\mathrm{mm})$ & 240 \\
Volumetric water content deficit, $\Delta W$ & 0.09 \\
Internal friction angle, $\varphi^{\prime}\left({ }^{\circ}\right)$ & 39.0 \\
\hline
\end{tabular}




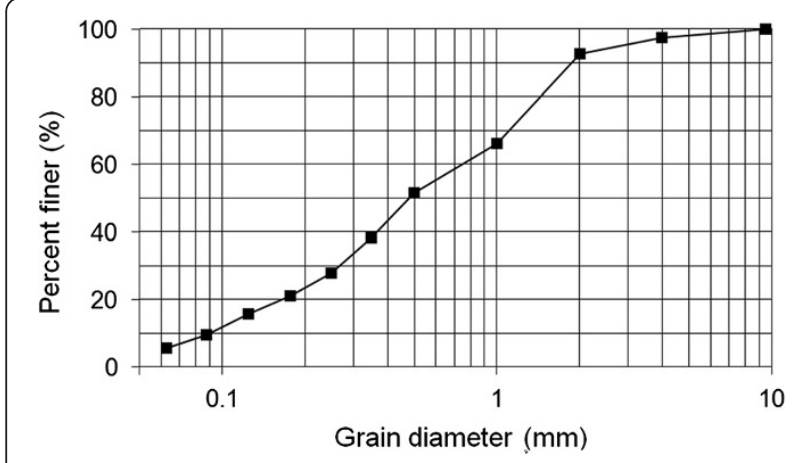

Figure 9 Grain-size distribution curve of a representative pumice sand.

greater than $6\left(C_{\mathrm{u}}=8.19\right)$, and a coefficient of curvature $\left(C_{\mathrm{c}}\right)$ between 1 and $3\left(C_{\mathrm{c}}=1.06\right)$.

Mechanical properties of the soils were obtained using static triaxial compression tests through a consolidatedundrained procedure. Pumice soil samples were remoulded to obtain five $\mathrm{cm}$ diameter and $10 \mathrm{~cm}$ high specimens with original in-situ density. To achieve the required density, the determined weight of the dry sample was inserted into a mould of specified volume, using dry pluviation method. In cases where there was excess soil mass, the moulds were impacted slightly to provide extra space for the remaining soil mass. The specimens were then injected with $\mathrm{CO}_{2}$ gas to replace the air inside it before it was saturated with deaired water. For undrained triaxial tests, Skempton (1954) introduced the pore pressure coefficient $B$ to express the pore water pressure change $\Delta u$ that occurs due to a change in confining pressure $\Delta \sigma_{3}$. The Skempton's $B$ value can be obtained by Eq. 13 .

$$
B=\frac{\Delta u}{\Delta \sigma_{3}}
$$

Full saturation of the specimens was confirmed if Skempton's $B$ value was greater than 0.95. After full saturation was reached, the specimens were loaded axially into a triaxial cell with differing confining pressures of $20 \mathrm{kPa}$ and $50 \mathrm{kPa}$, with displacement velocity of $0.7 \mathrm{~mm} /$ minute. The undrained strength parameters obtained are summarized in Table 2.

Stress-controlled cyclic triaxial tests (CTX) were performed to study the behaviour of the soils under cyclic loading. The specimen reconstitution procedures were similar to those in the static triaxial compression tests. The cyclic triaxial tests were performed to study the effect of cyclic loading on the fully saturated part of the landslide mass. The tests were conducted at different effective confining pressures $\left(\sigma_{0}^{\prime}\right)$ and initial shear stresses to examine the effect of overburden pressure and ground sloping condition under cyclic loading (Table 3). However,
Table 3 Summary of CTX tests conducted during this study

\begin{tabular}{lllll}
\hline No & Test ID & B values & $\boldsymbol{\phi}^{\prime}(\mathbf{k P a})$ & $\boldsymbol{K}$ \\
\hline 1 & TND45-0 & 0.980 & 45 & 0 \\
2 & TND45-0.2 & 0.970 & 45 & 0.2 \\
3 & TND45-0.3 & 0.980 & 45 & 0.3 \\
4 & TND45-0.4 & 0.980 & 45 & 0.4 \\
5 & TND90-0 & 0.960 & 90 & 0 \\
6 & TND135-0 & 0.980 & 135 & 0 \\
7 & TND60-0 & 0.980 & 60 & 0 \\
8 & TND75-0 & 0.990 & 75 & 0 \\
9 & TND100-0 & 0.980 & 100 & 0 \\
10 & TND120-0 & 0.980 & 120 & 0 \\
\hline
\end{tabular}

to focus on field conditions, initial relative density was maintained as the actual relative density measured in-situ.

The test procedure was performed in a manner to simulate the stress condition in the field. At first, the specimens were consolidated with specified confining pressure after full saturated condition has been attained. As an approximation of the irregular motion of earthquake loading, the amplitude of cyclic sinusoidal deviatoric axial stress was taken to be $65 \%$ of the maximum magnitude of shear stress induced by the actual earthquake, as proposed by Seed et al. (1975). The cyclic sinusoidal axial stresses were then applied to the specimens at a rate of $1 \mathrm{~Hz}$ until the ultimate failure state was achieved.

\section{Pore pressure model}

This paper developed a new approach to predict pore pressure increase by assuming reciprocal relationships between strain, stiffness and pore pressure (Figure 10), with fewer parameters required. The formulations here are based on experimental data from stress-controlled cyclic triaxial tests, using the original samples from the study area. The effects of initial shear stress were also included in the analysis, to develop a reliable constitutive model for sloping ground conditions.

The rule of shear strain on liquefaction and stiffness degradation has been confirmed in many researches. Lenart (2008), Jafarian et al. (2012) and Green et al. (2000) assessed strain energy-based excess pore pressure generation by considering strain-stress relationship. Lee and Sheu (2007) proposed stiffness degradation model which depends on cyclic strain history under cyclic straining. In this study, therefore, shear strain was assumed to be the leading factor of pore pressure increase, which consequently reduces shear stiffness as effective confining pressure decreases. However, the subsequent degraded stiffness value generates larger strain at the next loading cycle, which increases pore pressure more rapidly (Figure 10). In detail, since saturated soil at the 


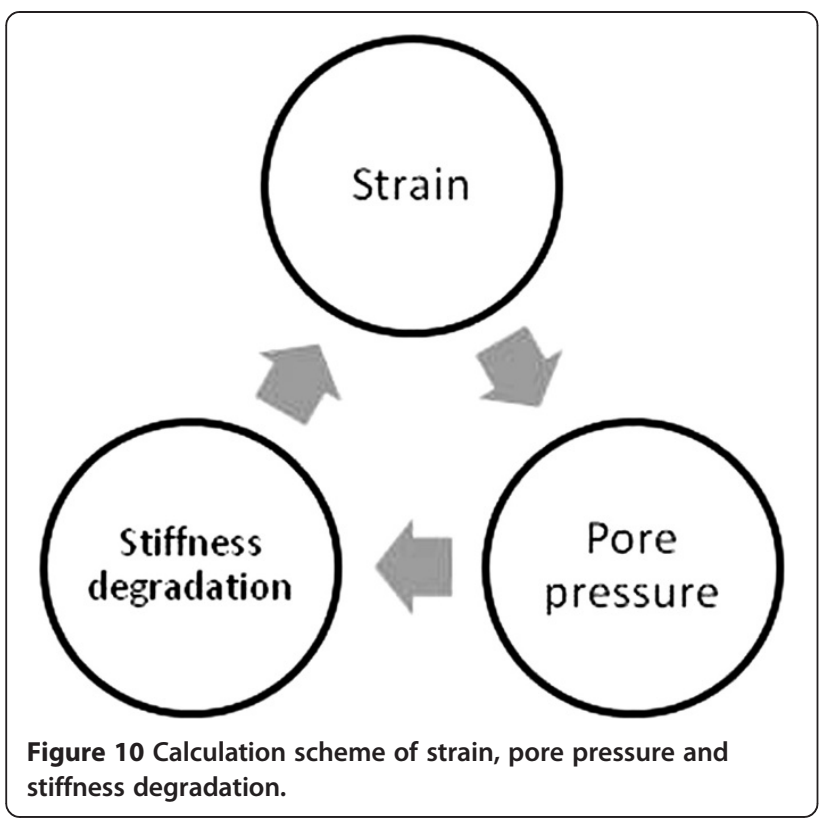

sliding surface surpasses its elastic threshold (ET) during early cyclic loading (Figure 11), the soil structure contracts, and pore pressure increases. The cyclic loading causes irreversible grain arrangement, and generates permanent excess pore pressure. The increase of pore pressure reduces effective stress, which consequently degrades the shear stiffness of the soil structure. At the next cycle, the soil structure is then subjected to the next loading, with current degraded shear stiffness leading to larger strain, which thus increases the pore pressure. This behaviour is considered to be a reciprocal relationship between plastic strains, pore pressure increase and shear stiffness degradation, which continues on every loading cycle. Based on this principle, cycle by cycle calculation procedure considering shear stiffness and strain dependency was performed. The predicted

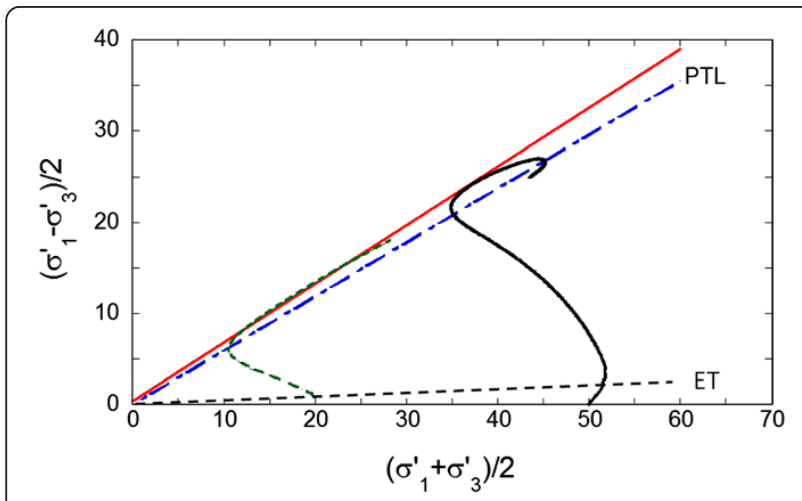

Figure 11 Effective stress path and transformed strength envelope of the static triaxial test. pore pressure was then used in slope stability analysis, using actual earthquake acceleration.

Figure 12 represents an idealized stress-strain loop for a specimen subjected to symmetric cyclic loading at the first cycle. This stress-strain loop is typically obtained from a routine CTX test, where the loop is related to the maximum values of cyclic axial strain and cyclic deviatoric stress. Curve OA is defined as the initial backbone curve, which characterizes stress-strain behaviour. The backbone curve has its initial slope $\left(E_{0}\right)$ at the origin; this slope is known as the maximum Young's modulus. The secant Young's modulus $\left(E_{\mathrm{s}}\right)$ is represented as the slope of the line connecting the original point with the tip of the loop associated with the axial strain amplitude $\left(\varepsilon_{\mathrm{s}}\right)$. The secant Young's modulus $\left(E_{\mathrm{s}}\right)$ and axial strain amplitude $\left(\varepsilon_{\mathrm{s}}\right)$ are the key properties of the developed non-linear constitutive model. These parameters were obtained at every cycle loading, to be correlated with the pore pressure increase.

To better incorporate the earthquake motion and the developed model, the term of shear stress and shear modulus was used instead of deviatoric stress and axial strain, although the data were obtained through triaxial tests. Assuming the soil behaves isotropically and elastically, the values of the secant shear modulus, $G_{s}$ and the shear strain amplitude, $\gamma_{\mathrm{s}}$ are defined by the equation:

$$
\begin{aligned}
& G_{\mathrm{s}}=\frac{E_{\mathrm{s}}}{2(1+\mu)} \\
& \gamma_{\mathrm{s}}=\varepsilon_{\mathrm{s}}(1+\mu)
\end{aligned}
$$

where $\mu$ is the Poisson's ratio equal to 0.5 for undrained conditions, and $E_{\mathrm{s}}, G_{\mathrm{s}}$ and $\gamma_{\mathrm{s}}$ are the secant Young's modulus, the secant shear modulus, and the shear strain amplitude, respectively. The initial shear modulus, $G_{0}$,

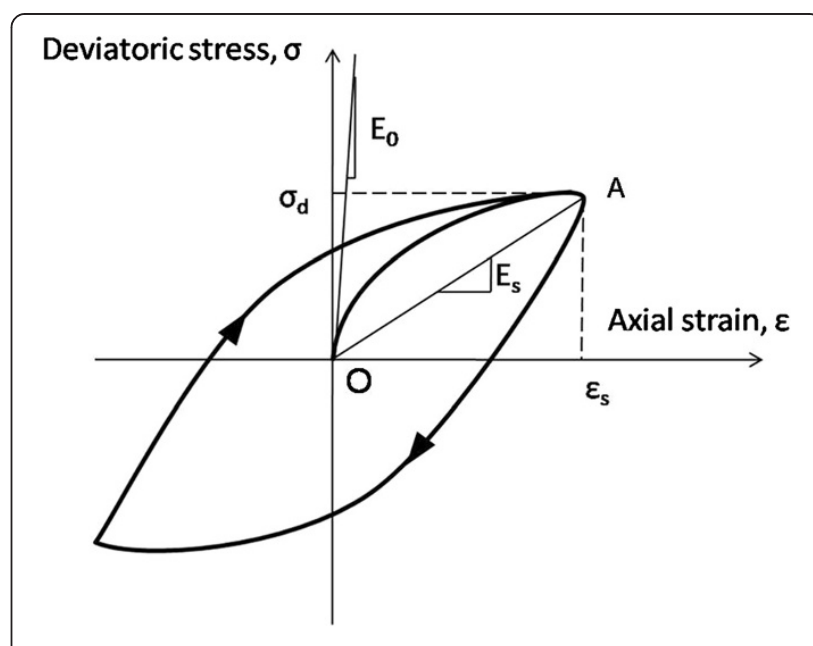

Figure 12 Typical stress-strain loop of the cyclic triaxial test. 
can be referred to Eq. 14 by changing parameter $E_{\mathrm{s}}$ to $E_{0}$.

\section{Results and discussion}

\section{Result of static triaxial test}

Static triaxial tests were conducted under $20 \mathrm{kPa}$ and $50 \mathrm{kPa}$ effective confining pressure to attain the shear strength of the pumice sand, and to understand its basic physical behaviour under stresses. The stress path (Figure 11) shows a large sector of contractive curve, implying the effect of pore pressure increase. It also indicates a low elastic threshold (ET), suggesting that the soil structure contracts easily under low shear stress. As the effective confining pressure decreases, the stress path exhibits dilation behaviour as it approaches the phase transformation line (PTL). This tendency of dilation after passing PTL suggests cyclic mobility behaviour when cyclic loading is applied (Ishihara 1985). From the test, the internal friction angle $\left(\phi^{\prime}\right)$ is equal to $39.0^{\circ}$.

\section{Typical result of cyclic triaxial test}

During earthquake movement, soil elements are influenced by cyclic shear stress working on a plane with constant normal stress. To appropriately simulate this condition, corrected pore pressure ratio $r_{\mathrm{u}}$ was used as the cyclic triaxial (CTX) test is conducted, by applying cyclic loads in the axial direction only (Žlender and Lenart 2005). Equation 16 of corrected pore pressure ratios $r_{\mathrm{u}}$ is used incorporating the $B$ value.

$$
r_{\mathrm{u}}=B\left(\frac{\Delta u-\frac{\sigma_{\mathrm{d}}}{2}}{\sigma_{0}^{\prime}}\right)
$$

where $\Delta u$ is the excess pore pressure, $\sigma_{\mathrm{d}}$ is the deviatoric axial stress, and $\sigma_{0}^{\prime}$ is the effective confining pressure.

The development of axial strain, the pore pressure ratio, the deviatoric stress-strain loop, and stress path during a CTX test of pumice sand under $45 \mathrm{kPa}$ effective confining pressure are shown in Figures 13, 14, 15 and 16, respectively. The shear-strain loop shows that the greatest stiffness occurred in the first stage of loading, and gradually decreased as cyclic loading proceeded. The stress path confirms cyclic mobility behaviour, where the pore pressure ratio rapidly increases in the first cycles, but did not necessarily reach liquefaction state until a large number of cycles had been completed (Figure 16). Cyclic mobility occurred due to dilation at low level mean effective confining pressure, where the pore pressure decreased and the mean effective confining pressure temporarily regained as the stress path passed the PTL. However, the specimen has already undergone larger strain before liquefaction was attained.

To assess shear strain and pore pressure increase in relation to effective confining pressure and initial shear stress, a reference cumulative shear strain was designated as the cumulative shear strain where $r_{\mathrm{u}}=0.8$, which is the inflation point of the $\gamma_{\mathrm{t}}-r_{\mathrm{u}}$ curve. Cumulative shear strain corresponding to $r_{\mathrm{u}}=0.8$ was considered to be the reference cumulative shear strain, $\gamma_{r}$, where, beyond this point, the pumice sand specimen underwent large strain without further significant pore pressure increase (Figure 17).

\section{Effect of effective confining pressure on reference cumulative shear strain}

As described in Table 3, the pumice sand samples were isotropically consolidated to seven different effective confining pressures, with $\sigma_{0}^{\prime}$ equal to $45 \mathrm{kPa}, 60 \mathrm{kPa}, 75 \mathrm{kPa}$, $90 \mathrm{kPa}, 100 \mathrm{kPa}, 120 \mathrm{kPa}$ and $135 \mathrm{kPa}$. As shown in the $\gamma_{\mathrm{t}}-r_{\mathrm{u}}$ curves, at each given effective confining pressure, pore pressure ratio increased rapidly at low cumulative shear strain (Figure 18). However, each effective confining pressure responded differently to pore pressure ratio increase during cyclic loading. Pore pressure ratio of the specimen with low confining pressure increased rapidly in response to cyclic loading, whereas pore pressure ratio at high confining pressure had a slower response to cyclic loading. At a given cumulative shear strain, pore pressure ratio clearly increases with decreasing effective confining pressure (Figure 18).

Figure 19 shows the correlation of $\sigma_{0}^{\prime}-\gamma_{\mathrm{r}}$ where $\gamma_{\mathrm{r}}$ increased with effective confining pressure, indicating that more cumulative strain was necessary to increase pore pressure at some level, as $\sigma_{0}^{\prime}$ increased. This suggests, therefore, that shallow saturated pumice sand deposits

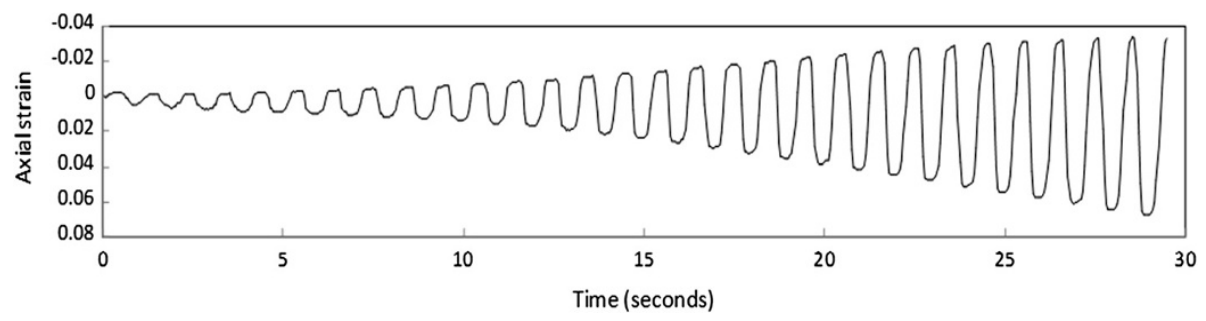

Figure 13 Time histories of cyclic axial strain at $\sigma_{0}^{\prime}=45 \mathrm{kPa}$. 


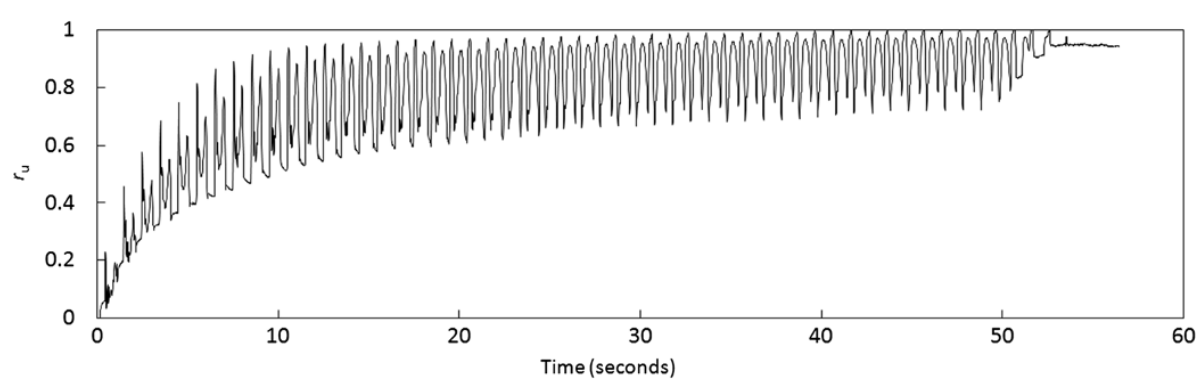

Figure 14 Time histories of excess pore water pressure ratio at $\sigma_{0}^{\prime}=45 \mathrm{kPa}$.

have higher risk of pore pressure increase during earthquakes than do deeper saturated sands.

\section{Effect of initial shear stress on reference cumulative shear strain}

As described in Table 3, CTX tests were conducted by applying initial shear stress at effective confining pressures of $\sigma_{0}^{\prime}=45 \mathrm{kPa}$. The degrees of initial shear stresses were set as $20 \%, 30 \%$ and $40 \%$ of the initial effective confining pressure, $\sigma_{0}^{\prime}$. Initial relative density was kept nearly the same at every level of initial shear stress $\left(D_{\mathrm{r}} \approx 50 \%\right)$. The ratio of initial shear stress to the initial effective confining pressure, $K$, is defined as:

$$
K=\frac{\tau_{\text {stat }}}{\sigma_{0}^{\prime}}
$$

Initial shear stress was applied after consolidation by applying additional axial stress $\left(\sigma_{\mathrm{d}}^{\prime}\right)$, with open drainage and low pace loading (about $1 \mathrm{kPa} /$ minute), to ensure drained condition in the specimen. The additional axial stress given to the specimen satisfied the equation:

$$
\sigma_{d}^{\prime}=2 \tau_{\text {stat }}
$$

The $\gamma_{\mathrm{t}}-r_{\mathrm{u}}$ curves of different initial shear stresses are presented in Figure 20. It shows the response in pore pressure increase of effective confining pressure $45 \mathrm{kPa}$,

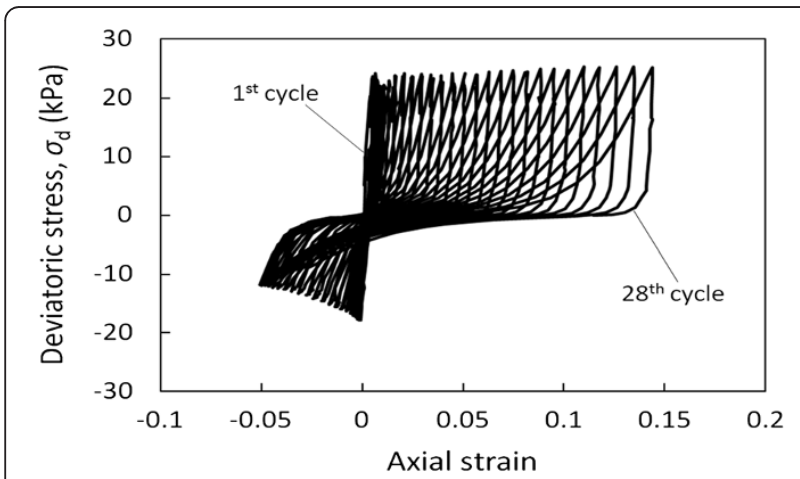

Figure 15 Deviatoric stress-axial strain loop at $\sigma_{0}^{\prime}=45 \mathrm{kPa}$. where the increase of initial shear stress reduced the response of pore pressure generation.

The effect of initial shear stress on the reference cumulative shear strain is more clearly shown in Figure 21. Initial shear stress clearly affects the relationship between pore pressure and reference cumulative shear strain (Figure 21). For the specimen with effective confining pressure of $45 \mathrm{kPa}$, the reference cumulative shear strain increases linearly with the initial shear stress ratio, $K$ (Figure 21). This suggests that, in a shallow deposit, soil mass with larger initial shear stress needs larger cumulative shear strain to increase pore pressure ratio to some certain value. From the viewpoint of slope stability analysis, this suggests that, particularly in the studied area where shallow deposit be present, gentle slopes are more prone to pore pressure build-up during earthquakes than are steep slopes.

\section{Effect of effective confining pressure on stiffness degradation}

A plot of secant shear modulus, $G_{\mathrm{s}}$ and cumulative shear strain, $\gamma_{\mathrm{t}}$ with different effective confining pressures (Figure 22) clearly shows that the effective confining pressure contributed to the initial shear modulus, $G_{0}$, which occurred at low strain. During cyclic loadings, the shear modulus decreased rapidly irrespective of the

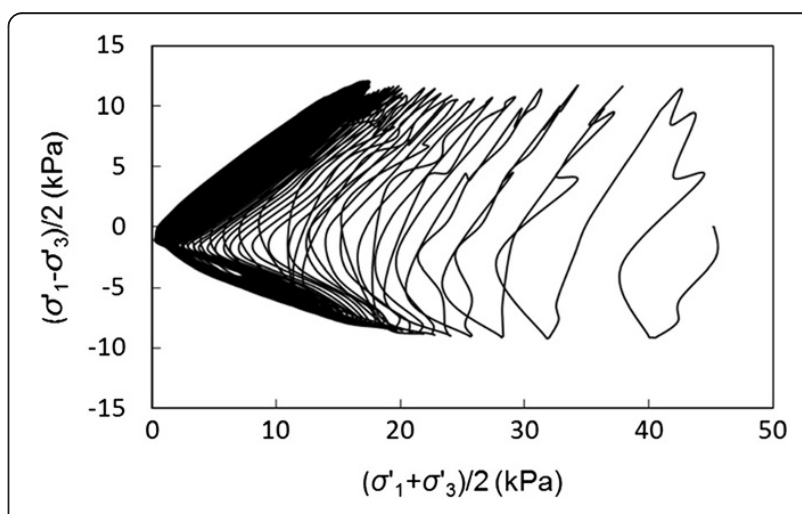

Figure 16 Effective stress path of mean confining pressure and shear stress at $\sigma_{0}^{\prime}=45 \mathrm{kPa}$. 


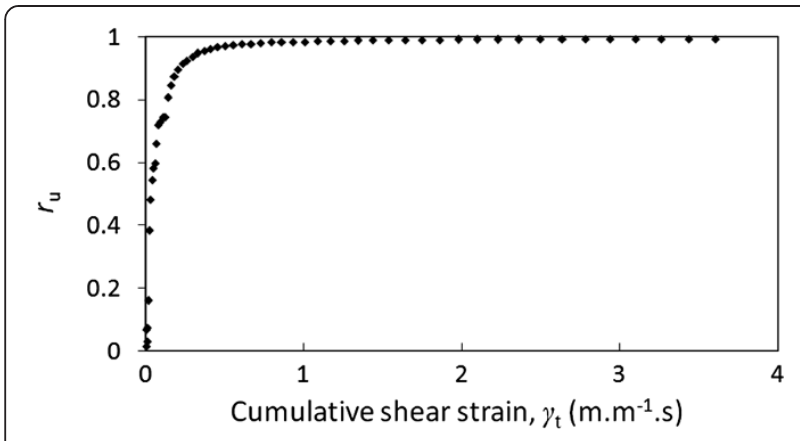

Figure 17 Excess pore water pressure ratio versus cumulative shear strain.

effective confining pressure. Initial shear moduli, $G_{0}$, were estimated during curve fitting of the secant shear modulus, $G_{\mathrm{s}}$ versus cumulative shear strain, by using the $G_{\mathrm{s}}-\gamma_{\mathrm{t}}$ curve fit equation:

$$
G_{\mathrm{s}}=\frac{G_{0}}{1+\beta \gamma_{\mathrm{t}}}
$$

where $\beta$ is a non-dimensional calibration parameter which involves effective confining pressure in the regression equation $\left(R^{2}=0.966\right)$ in Eq. 20 .

$$
\beta=-655.5 \sigma_{0}^{\prime}+10266
$$

From Figures 23, 24 and 25, the estimated initial shear moduli, $G_{0}$, of effective confining pressure of $45 \mathrm{kPa}$, $90 \mathrm{kPa}$ and $135 \mathrm{kPa}$ were $80 \mathrm{MPa}, 200 \mathrm{MPa}$ and $250 \mathrm{Mpa}$, respectively.

Effect of initial shear stress on stiffness degradation The plot secant shear modulus, $G_{\mathrm{s}}$ vs cumulative shear strain, $\gamma_{\mathrm{t}}$ corresponding to initial shear stress ratio, $K$ of

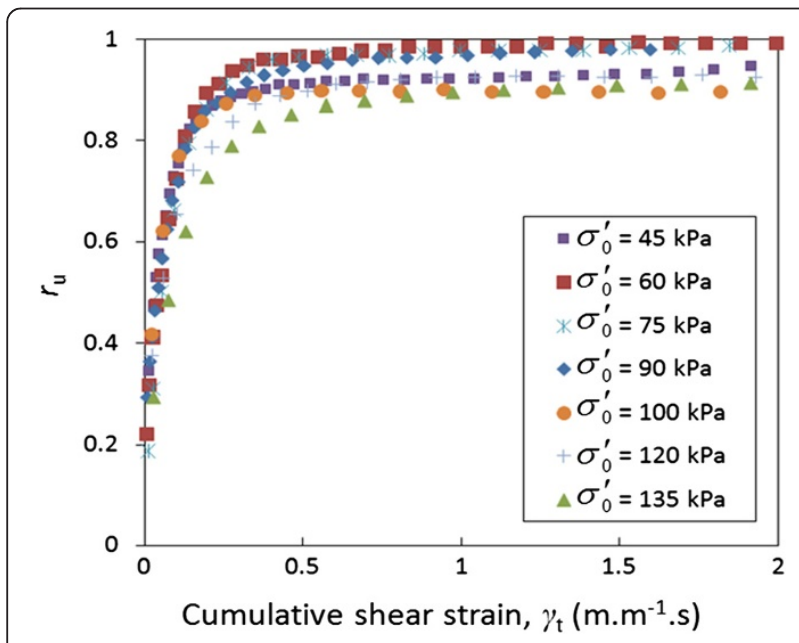

Figure 18 Excess pore water pressure ratio versus cumulative shear strain for various effective confining pressures.

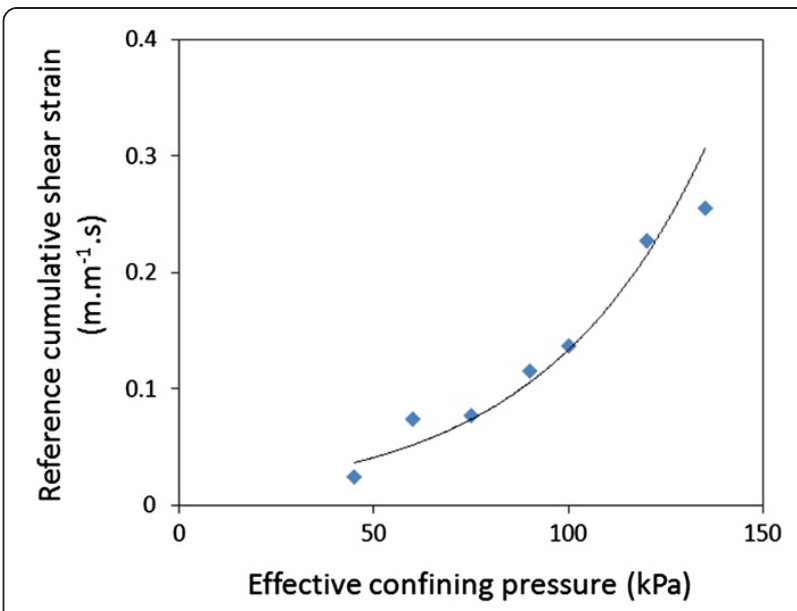

Figure 19 Reference cumulative shear strain vs effective confining pressure.

$45 \mathrm{kPa}$ effective confining pressure are shown in Figure 23. The effect of initial shear stress, $K$, on shear stiffness degradation is not clearly observable. The plot shows the same tendency, and insignificant differences of initial shear modulus, $G_{0}$, at every different values of $K$. Therefore, the influence of initial shear stress on stiffness degradation is negligible.

\section{Numerical analysis}

\section{Pore pressure model fitting}

Several model forms were examined to predict the regional risk of pore pressure increase during the earthquake, based on experimental data of the $\gamma_{\mathrm{t}}-r_{\mathrm{u}}$ relationship. The following equation was fitted to the data:

$$
r_{u}=\left(1+\frac{1}{\alpha \gamma_{t}}\right)^{-1}
$$

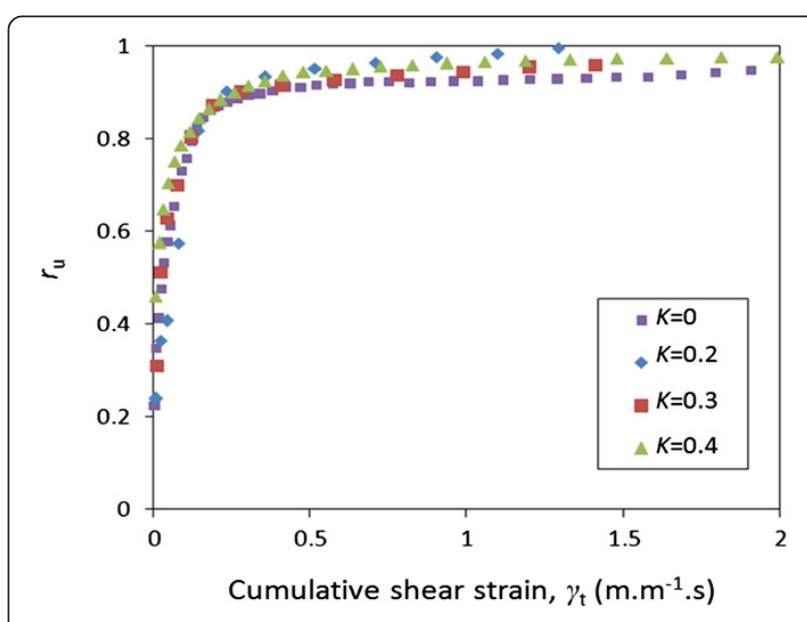

Figure 20 Pore pressure ratio for $\sigma_{0}^{\prime}=45 \mathrm{kPa}$ versus cumulative shear strain with various shear stress ratios. 


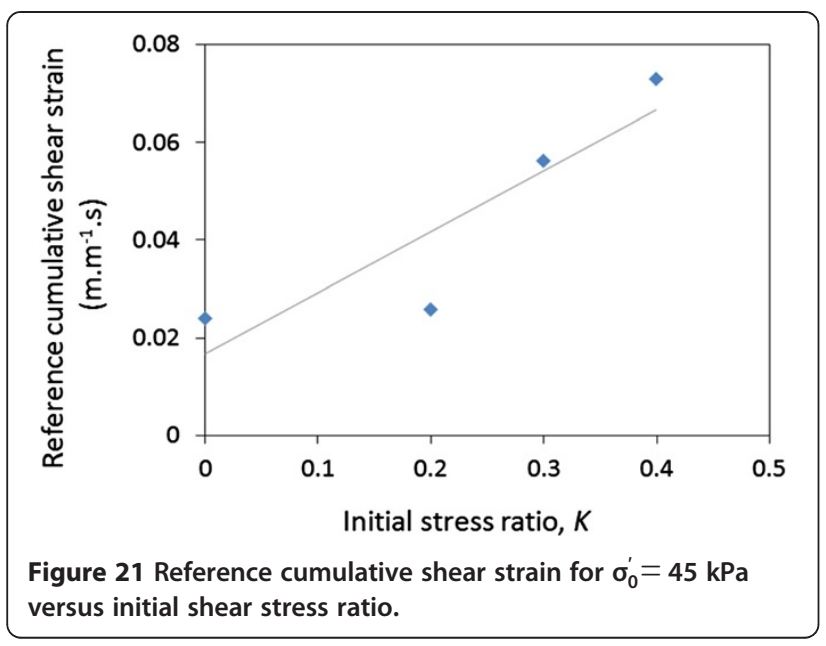

where $\alpha$ is a non-dimensional calibration parameter of the pore pressure model, and $\gamma_{\mathrm{t}}$ is the cumulative shear strain. From a practical viewpoint, $\gamma_{\mathrm{t}}$ can be estimated over numerical analysis by considering a constitutive model that can simulate the non-linear stress-strain response of the soil undergoing rapid pore pressure increase, which will be discussed later in a subsequent section. Using linear regression, the calibration parameter $\alpha$ was correlated with effective confining pressure, $\sigma_{0}^{\prime}$ and the initial shear stress ratio, $K$. The following linear regression of $\alpha$ involves parameter $\sigma_{0}^{\prime}$ and $K$ in the Eq. $22\left(R^{2}=0.951\right)$.

$$
\alpha=-0.54 \sigma_{0}^{\prime}-48.5 .5 K+90.85
$$

In this study, the non-linearity of stress-strain were also implemented by correlating cumulative shear strain, $\gamma_{\mathrm{t}}$ and the secant shear modulus, $G_{\mathrm{s}}$. The influence of effective confining pressure and initial shear stress on shear stiffness degradation was also examined through data obtained from the CTX tests.

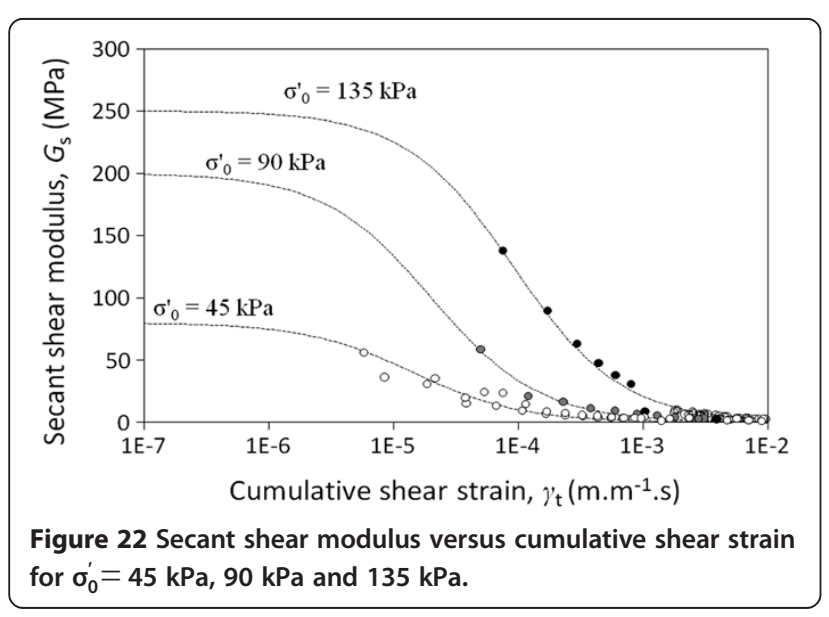

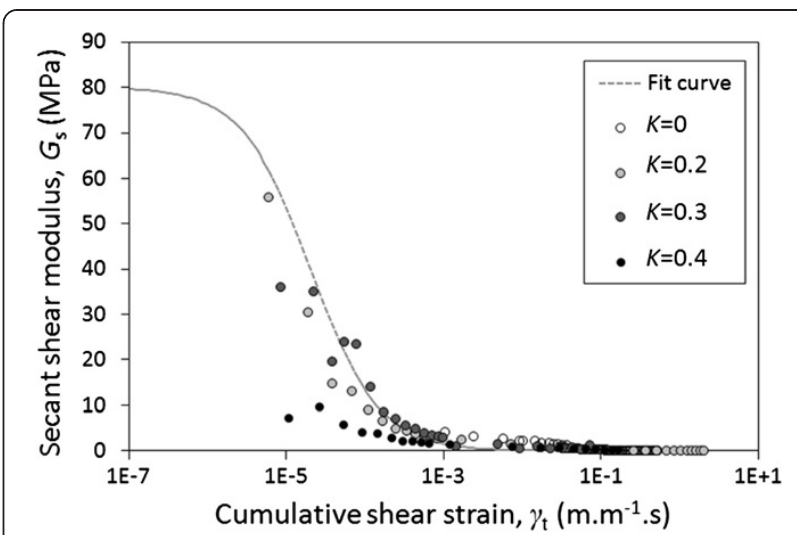

Figure 23 Secant shear modulus versus cumulative shear strain for $\sigma_{0}^{\prime}=90 \mathrm{kPa}$ with variable shear stress ratio.

The best fit curve showing the relationship of $G_{\mathrm{s}}-\gamma_{\mathrm{t}}$ is expressed by Eq. 19. The equation implies that shear strain $\left(\gamma<10^{-5}\right)$ near zero will transform the equation to $G \approx G_{0}$, and the increased cumulative shear strain will gradually decrease the secant modulus.

\section{Rigid block on quasi-plastic layer and simulation procedure}

A model of a rigid block on a quasi-plastic layer was used to simulate the earthquake-soil interaction involving non-linearity of stress-strain and pore pressure increase (Figure 26). This model was derived by assuming that the pumice sand layer rested on a firm impermeable base, as observed in the field. The thin basal shear zone of pumice layer was assumed to be fully saturated during rainfall, and liquefiable when pore pressure increase occurred. In this model, the saturated layer behaves elastically in every cyclic loading where secant shear modulus, $G_{\mathrm{s}}$ involves in stress-strain interaction, whereas the unsaturated portion of the pumice sand layer was assumed to act as a rigid body. However, during earthquake loadings, increasing shear stress develops large shear strain,

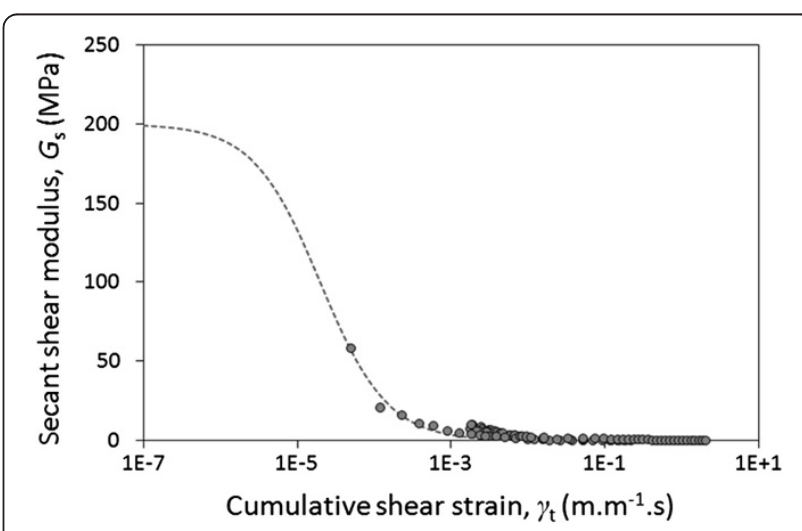

Figure 24 Secant shear modulus versus cumulative shear strain for $\sigma_{0}^{\prime}=90 \mathrm{kPa}$. 


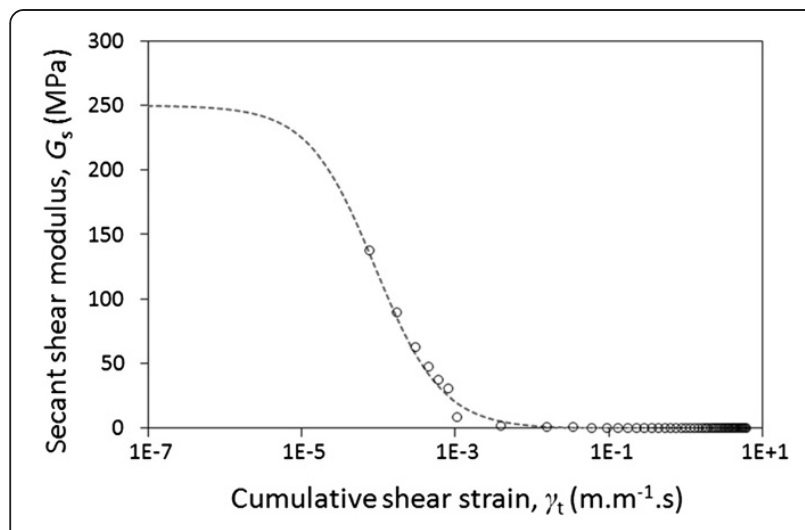

Figure 25 Secant shear modulus versus cumulative shear strain for $\sigma_{0}^{\prime}=135 \mathrm{kPa}$.

which reduces the secant shear modulus, $G_{\mathrm{s}}$. Therefore, the next cycle of loadings may generate larger shear strain due to the previously reduced shear modulus. This process results in irrecoverable shear strain in the cyclic loading time history, which is the reason of the use of the term "quasi plastic". Slope stability analysis was also incorporated with the model, in the manner of infinite slope assumption. To explain this process, Eq. 19 can be also be recast as follows:

$$
G_{\mathrm{s}}^{n}=\frac{G_{\mathrm{s}}^{n-1}}{1+\beta \gamma_{\mathrm{t}}^{n}}
$$

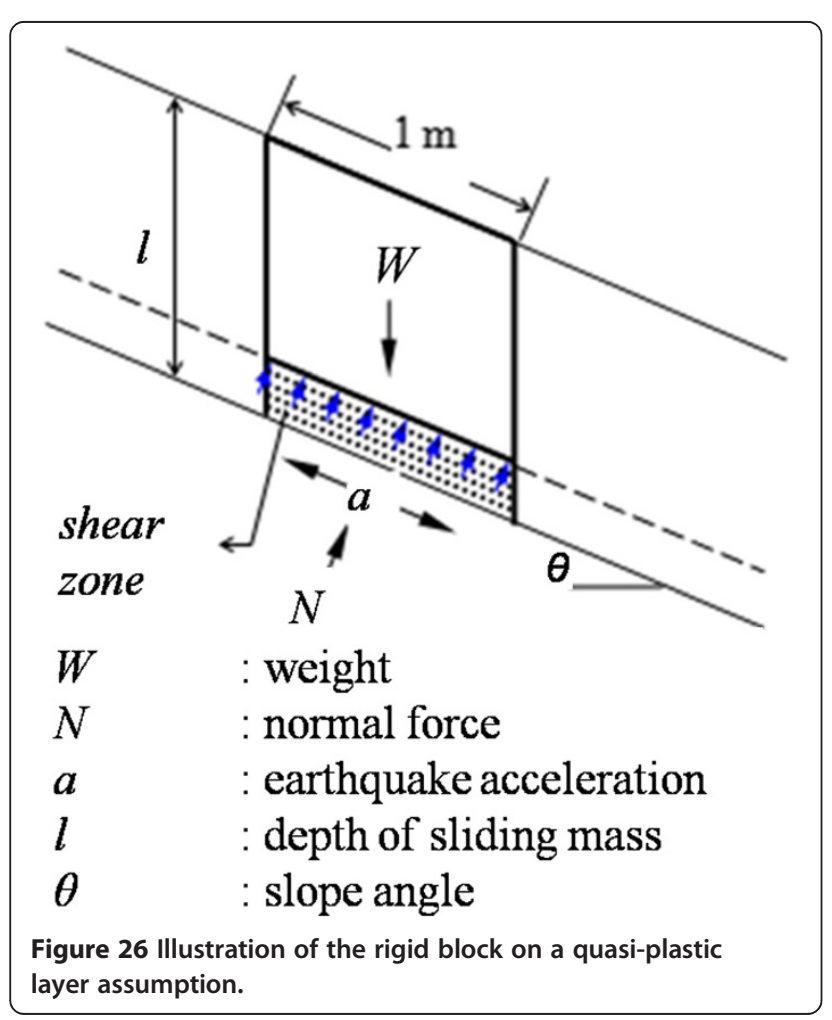

where superscript $n$ represents the number of calculation steps. At the first calculation step $(n=1)$, the initial value of $G_{\mathrm{s}}$ is set as equal to $\mathrm{G}_{0}$. The strain is calculated based on the Eq. 24, which satisfies the elastic assumption:

$$
\gamma_{\mathrm{s}}^{n}=\frac{\tau_{\mathrm{d}}^{n}}{G_{\mathrm{s}}^{n}}
$$

where $\tau_{\mathrm{d}}$ is shear stress taken from dynamic loadings at step $n$. In the case of the earthquake, forces are calculated over a unit surface, and therefore shear stress $\tau_{\mathrm{d}}$ is simply determined as:

$$
\tau_{\mathrm{d}}=m \times a_{\mathrm{e}}
$$

where $m$ is the mass and $a_{\mathrm{e}}$ is the earthquake acceleration working parallel to the slope.

The cumulative shear strain was calculated (Eq. 26) and subsequently used in Eq. 21. The obtained excess pore water pressure ratio then used in Eq. 27 to get total pore water pressure.

$$
\begin{aligned}
& \gamma_{\mathrm{t}}=\int_{t=0}^{t=t_{\mathrm{n}}} \gamma_{\mathrm{s}} d t \\
& u_{\mathrm{t}}^{n}=u_{\mathrm{i}}+r_{\mathrm{u}} \sigma_{0}^{\prime}
\end{aligned}
$$

where $t_{n}$ is the time of $n^{\text {th }}$ step, $u_{\mathrm{t}}$ is total pore water pressure, $u_{\mathrm{i}}$ is initial pore water pressure defined in Eq. 28 just before earthquake happen.

$$
u_{\mathrm{i}}=\gamma_{\mathrm{w}} h \cos ^{2} \theta
$$

where $\gamma \mathrm{w}$ is the unit weight of water $(9.81 \mathrm{kN} / \mathrm{m} 3), h$ is the height of phreatic line from the sliding surface obtained by groundwater simulation (Eq. 9) and $\theta$ is the slope angle.

Infinite slope assumption was used to analyze the slope stability. The factor of safety $\left(F_{\mathrm{s}}\right)$ was calculated using the equation:

$$
F_{\mathrm{s}}=\frac{c^{\prime}+\left(\gamma l \cos ^{2} \theta-u_{\mathrm{i}}\right) \tan \phi^{\prime}}{\gamma l \cos \theta \sin \theta+\frac{k_{\mathrm{h}} \gamma l}{\cos \theta}}
$$

where $c^{\prime}$ is effective cohesion, $\phi^{\prime}$ is the effective friction angle, $\gamma$ is the unit weight of the sliding mass, $l$ is the depth of the sliding mass and $k_{\mathrm{h}}$ is the coefficient of horizontal earthquake acceleration.

For the case of negligible cohesion, Eq. 29 can be simplified as:

$$
F_{\mathrm{s}}=\frac{\left(\gamma l \cos ^{2} \theta-u_{\mathrm{i}}\right) \tan \phi^{\prime}}{\gamma l \cos \theta \sin \theta+\frac{k_{\mathrm{h}} \gamma}{\cos \theta}}
$$

A series of CTX triaxial test results were used to verify the rigid block on quasi-plastic layer method. The input of shear stress from the test was used to back-predict 


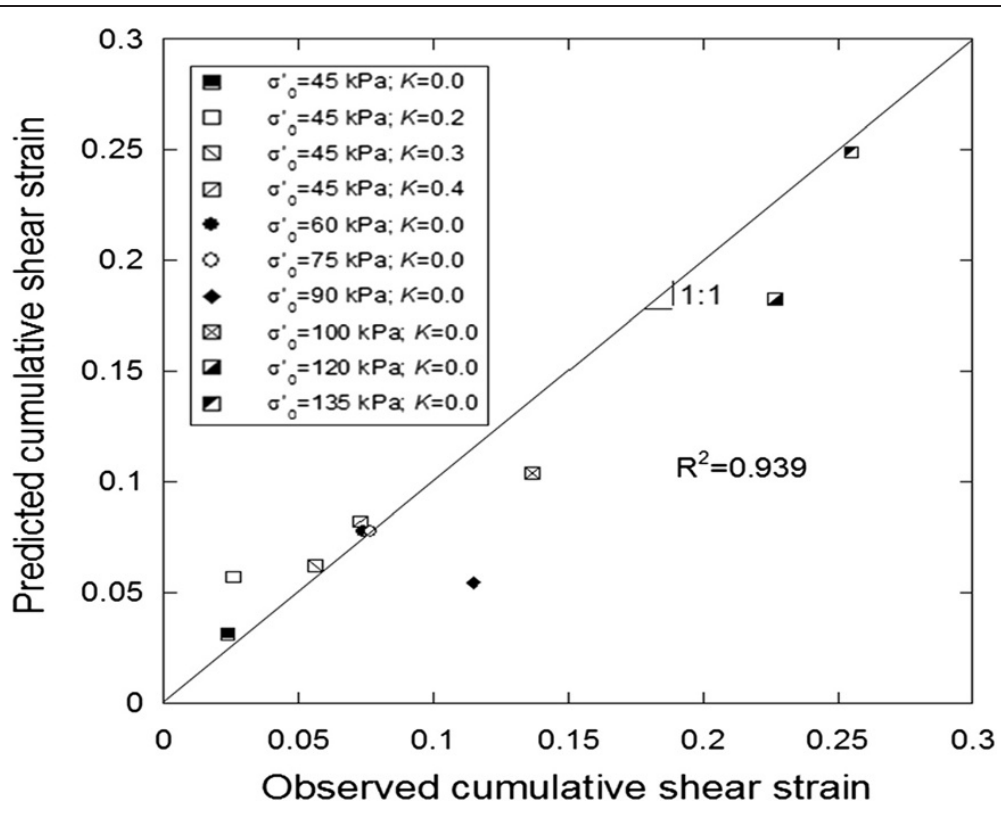

Figure 27 Performance of the rigid block on quasi-plastic layer method on reference cumulative shear strain prediction at different confining pressures and initial shear stress ratios.

shear strain and pore pressure ratio, using rigid block on quasi-plastic layer procedures. The performance of the rigid block on quasi-plastic procedure was tested by plotting predicted values against experimental cumulative shear strains from 10 CTX tests (Figure 27). The model achieved reasonable prediction $\left(R^{2}=0.939\right.$; Figure 27$)$, but some inaccuracies occur. These inaccuracies were probably due to error accumulation during the regression and calibration process.

Pore pressure simulation and slope stability analysis during actual earthquake

Finite element procedure using two dimensional finite element code software (ABAQUS 2D) was implemented to estimate the earthquake acceleration in the landslide shear zone during the actual earthquake motion. The estimated acceleration was then used to evaluate slope stability during earthquake motion by predicting pore water pressure build-up, based on a developed pore pressure model. The slope stability analysis was conducted by considering acceleration obtained from ABAQUS 2D, and a pore pressure model developed from laboratory test results. The analysis focused on three elevations of the sliding zone, at the toe, middle and crest of the slope (Figure 28).

The slope stability analysis was conducted utilizing a rigid block on a quasi-plastic layer procedure, base on infinite slope assumption, as depicted in Figure 26. The

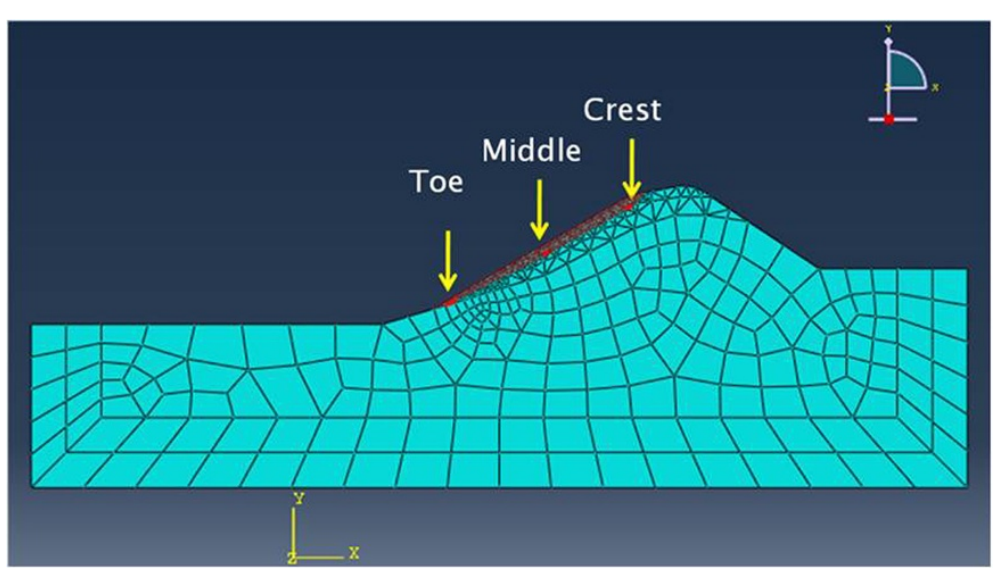

Figure 28 Model of ABAQUS 2D FEM and slope stability analysis points. 
soil strength parameters from Table 1 were used as resisting components, along with the actual horizontal earthquake acceleration of the $M_{w}$ 7.6 Padang earthquake. The results of pore pressure simulation and slope stability analysis are presented in Figure 29, as time history of earthquake acceleration, pore pressure, and factor of safety $(F o S)$. In each section, initial pore pressure generated from groundwater model was included. In the slope toe section, the pore pressure ratio presented by $r_{\mathrm{u}}$ curve increased rapidly in the first $17 \mathrm{~s}$ to unity, indicating the occurrence of liquefaction (Figure 29a). However, the factor of safety fell in accordance with the increase of pore pressure, reaching the failure state in $13 \mathrm{~s}$, suggesting immediate failure due to pore pressure increase. This apparently shows that failure of the slope toe occurred before the maximum acceleration was reached, and that failure was strongly induced by pore water pressure increase. In contrast, failure of middle part and the crest slope occurred due to the combination of acceleration amplification and pore pressure build-up (Figure 29b and c, respectively).

This analysis shows that the slope would fail due to earthquake shaking, even without pore pressure increase.
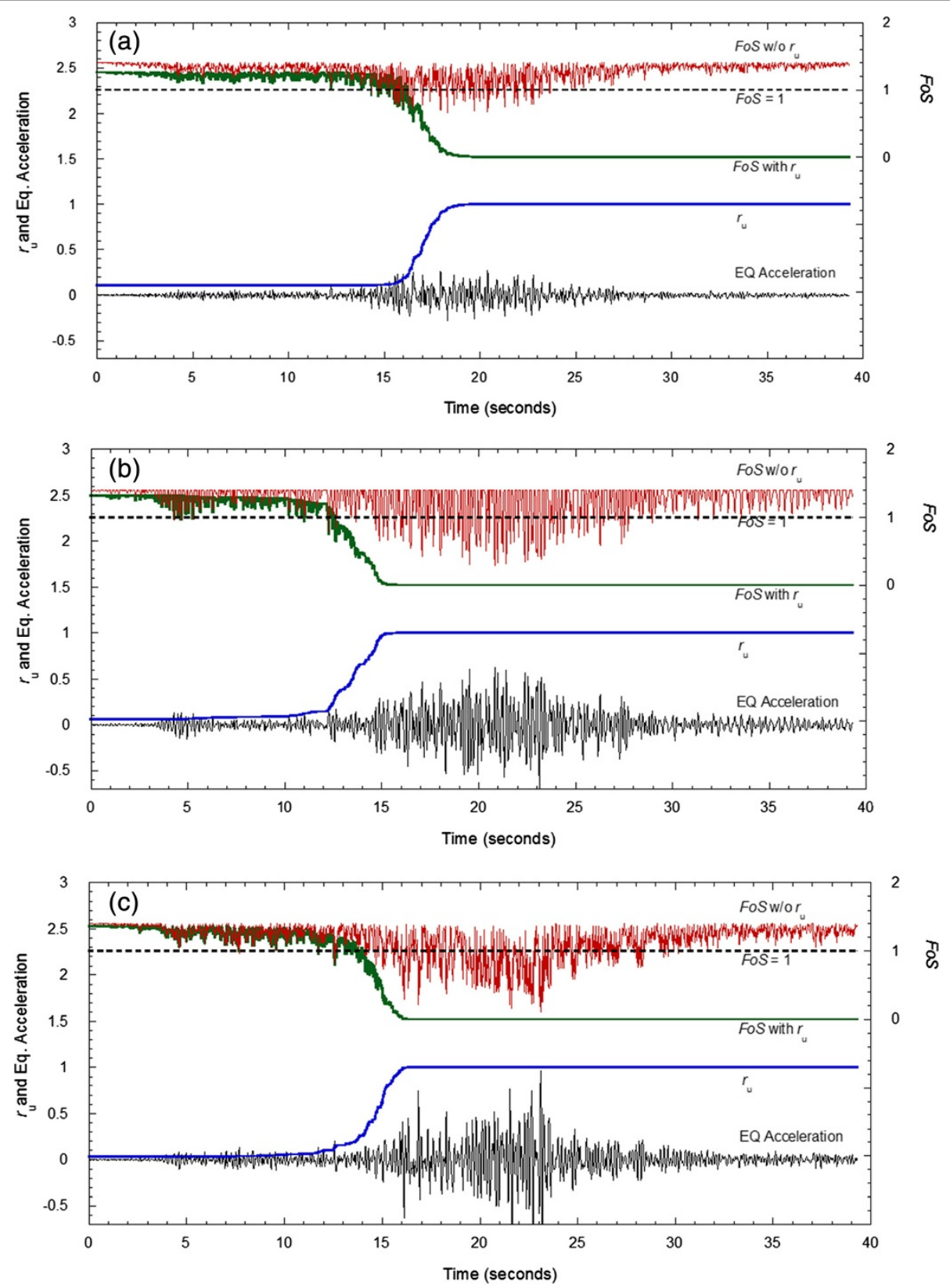

Figure 29 Time history of earthquake acceleration, pore pressure ratio $\left(r_{u}\right)$, factor of safety (FoS) considering $r_{u}\left(F o S\right.$ with $\left.r_{u}\right)$ and without considering $r_{\mathrm{u}}$ (FoS w/o $r_{\mathrm{u}}$ ) at the a. toe; b. middle; and c. crest. 
However, because the Tandikat landslide occurred during rainfall and underwent flow mobility, "dry" failure did not occur. Hence, "wet" failure, where the sliding zone reached a fully saturated condition is more realistic. The immediate and rapid failure of the slope before earthquake acceleration reached its peak shows that the saturated slope mass of loose pumice sand needs only slight energy to generate shear strain, which then increased the pore pressure to a critical and catastrophic level. This suggests that earthquake of smaller magnitude than the M7.6 2009.9.30 Padang earthquake can still lead to disaster if the required condition of sliding zone saturation due to rainfall is attained.

\section{Conclusions}

Based on field observations, the pumice sand was the main material of the extensive landslide mass. The low density and high porosity of the pumice sand contributed to the slope failure induced by earthquake during rainfall.

The possibility of rainfall saturation of the pumice sand deposit was assessed using the Green-Ampt method. The results suggested that the sliding zone of the pumice sand deposits less than $3 \mathrm{~m}$ had a high probability of saturation by rainfall infiltration. High permeability and high water content due to antecedent rainfall facilitated rainfall water percolation into the ground.

Vulnerability of saturated pumice sand to pore pressure increase was confirmed by static and stress-controlled cyclic triaxial tests, which showed contractive behaviour of the pumice deposits, as indicated by excess pore pressure rise at small strains. Immediate pore pressure build-up occurred when fully saturated specimens were tested.

CTX test results showed that effective confining pressure greatly influenced reference cumulative shear strain. The test results showed that reference cumulative shear strain increased linearly with effective confining pressure, suggesting that risk of pore pressure increase during earthquake was greater in saturated shallow pumice sand deposits than in than thicker deposits.

The effect of initial shear stress on reference cumulative shear strain was also examined. The results indicate that soil mass with larger initial shear stress needs larger cumulative shear strain to increase pore pressure ratio to a certain value. This suggests that pore pressure increase during earthquake is more probable on gentle slopes than it is on steep slopes.

The phenomenon of stiffness degradation of pumice sand during cyclic loading was also considered. The effect of effective confining pressure on stiffness degradation was obvious, while the effect of initial shear stress was unclear. These results indicated that the effective confining pressure contributed to the initial shear modulus, $G_{0}$, which is the initial value of the secant shear modulus $G_{\mathrm{s}}$.
During cyclic loading, the shear modulus decreased rapidly irrespective of the effective confining pressure.

Stability analysis of the Tandikat landslide using a rigid block on a quasi-plastic layer assumption and the actual earthquake acceleration suggested that slope failure occurred due to pore pressure build-up. The factor of safety decreased rapidly before earthquake acceleration peaked. At that time, the energy of the earthquake had not reached its maximum level, suggesting that failure would probably occur on saturated sliding zone even during smaller earthquakes. This finding emphasises the high risk of catastrophic earthquake-triggered landslides in tropical regions with high rainfall.

\section{Competing interests}

The authors declare that they have no competing interests.

\section{Authors' Contributions}

FF carried out field investigations, laboratory test, numerical modelling and manuscript preparation. FW facilitated laboratory apparatuses and field investigation equipments, provided suggestions and advices to the study and checked the manuscript. All authors read and approved the final manuscript.

\section{Acknowledgements}

We appreciate the help of Prof. Dwikorita Karnawati and Dr. T. Faisal Fathani of Gadjah Mada University for providing additional data (SPT and geological logging) used in this study. We are also grateful to Mr. Rahindro Pandhu Mahesworo, S.T, M.T, the Head of Engineering Seismology Data, BMKG Indonesia, for providing the earthquake accelerogram data used in this study. We also express thank to Prof. Barry Roser of Shimane University and Austin O. Chukwueloka for their review of an early draft of the manuscript.

Received: 21 August 2014 Accepted: 27 August 2014

Published online: 03 October 2014

\section{References}

Aydan Ö (2009) A reconnaissance report on the Pariaman-Padang earthquake of September 30, 2009. Japan Society of Civil Engineers, Japan, p 36

Bansal RK (2013) Modelling of groundwater flow over sloping beds in response to constant recharge and stream of varying water level. (in press). http://www.ijm2c.ir/index.php/ijm2c/article/view/108/150 [last accessed: June 29, 2014]

Bansal RK, Das SK (2010) An analytical study of water table fluctuations in unconfined aquifers due to varying bed slopes and spatial location of the recharge basin. J Hydrol Eng 15(11):909-917

Chen L, Young MH (2006) Green-Ampt infiltration model for sloping surfaces. Water Resource Res 42:1-9

EERI (2009) Learning from earthquakes: the MW 7.6 Western Sumatra earthquake of September 30, 2009. http://www.eeri.org/site/images/eeri_newsletter/ 2009_pdf/Padang-eq-report-NL-insert.pdf [last accessed: April 8, 2013]

Green WH, Ampt GA (1911) Studies on soil physics: 1. Flow of air and water through soils. J Agric Sci 4:1-24

Green RA, Mitchell JK, Polito CP (2000) An energy-based excess pore pressure generation model for cohesionless soils. Proceedings of the John Booker Memorial Symposium. Sydney, New South Wales, Australia, November 16-17, 2000. A.A. Balkema Publishers, Rotterdam

Hsu S-M, Ni C-F, Hung P-F (2002) Assessment of three infiltration formulas based on model fitting on Richard's equation. J Hydrol Eng 7(5):373-379

Hyodd M, Hyde AFL, Aramaki N (1998) Liquefaction of crushable soils. Géotechnique 48(4):527-543

Ishihara K (1985) Stability of natural deposits during earthquakes. Proceedings, $11^{\text {th }}$ International Conference on Soil Mechanics and Foundation Engineering, San Francisco, Vol. 1. pp 321-376

Jafarian Y, Towhata I, Baziar MH, Noorzad A, Bahmanpour A (2012) Strain energy based evaluation of liquefaction and residual pore water pressure in sands using cyclic torsional shear experiments. Soil Dynam Earthq Eng 35:13-28 
Lee KL, Albaisa A (1974) Earthquake-induced settlement in saturated sands. J Soil Mech Found Div ASCE 100:387-406

Lee CJ, Sheu SF (2007) The stiffness degradation and damping ratio evolution of Taipei Silty Clay under cyclic straining. Soil Dynam Earthq Eng 27:730-740

Lenart S (2008) The use of dissipated energy at modeling of cyclic loaded saturated soils. Earthquake Engineering: New Research. Nova Science Publishers, Inc., New York

Marks S, Larkin TJ, Pender MJ (1998) The dynamic properties of a pumiceous sand. NZNSEE Bull 31(2):86-100

Muñoz-Carpena R, Regalado CM, Álvarez-Benedí J, Bartoli F (2002) Field evaluation of the new Philip-Dunne permeameter for measuring saturated hydraulic conductivity. Soil Sci 167:9-24

Orense RP, Pender MJ (2013) Liquefaction characteristics of crushable pumice sand, Proceeding of the $18^{\text {th }}$ International Conference on Soil Mechanics and Geotechnical Engineering. 2-6 September, Paris. pp 1559-1562

Petersen M, Harmsen S, Mueller C, Haller K, Dewey J, Luco N, Crone A, Lidke D, Rukstales K (2007) Documentation for the Southeast Asia seismic hazard maps. Administrative report, U.S. Geological Survey. p 67

Philip JR (1993) Approximate analysis of falling-head lined borehole permeameter. Water Resource Res 29:3763-3768

Regalado CM, Ritter A, Álvarez-Benedí J, Muñoz-Carpena R (2005) Simplified method to estimate the Green-Ampt wetting front suction and soil sorptivity with the Philip-Dunne falling-head permeameter. Vadose Zone Journal 4:291-299

Seed HB, Idriss IM, Makdisi F, Banerjee N (1975) Representation of irregular stress time histories by equivalent uniform stress series in liquefaction analyses, Report No EERC 75-29, Earthquake Engineering Research Centre. University of California, Berkley

Seed HB, Martin PP, Lysmer J (1976) Pore water pressure change during soil liquefaction. J Geotech Eng Div ASCE 102(4):323-346

Sipayung SB, Lely QA, Bambang DD, Sutikno A (2007) The analysis of rainfall pattern in Indonesia based on global circulation model (GCM) output. Jurnal Sains Nusantara 4(2):145-154, in Indonesian

Skempton AW (1954) The pore pressure coefficients A and B. Geotechnique 4:143-7

Sloan PG, Moore ID (1984) Modeling subsurface stormflow on steeply sloping forested watersheds. Water Resources Res 20:1815-1822

Steenhuis TS, Parlange JY, Sanford WE, HeiligA SF, Walter MF (1999) Can we distinguish Richards' and Boussinesq's equations for hillslopes?: The Coweeta experiment revisited. Water Resources Res 35(2):589-593

Sugano T, Yanagisawa E (1992) Cyclic undrained shear behaviour of sand under surface wave stress conditions, Tenth World Conference of Earthquake Conference, Balkema, 19-24 July, Madrid, Spain., pp 1323-1327

Suzuki M, Yamamoto T (2004) Liquefaction characteristic of undisturbed volcanic soil in cyclic triaxial test, Proceeding of $13^{\text {th }}$ World Conference of Earthquake Engineering, 1-6 August 2004, Vancouver, B.C., Canada, paper no. 465

Wang FW, Sassa K (2000) Relationship between grain crushing and excess pore pressure generation by sandy soils in ring shear tests. J Nat Disaster Sci 22(2):87-96

Wang FW, Muhammad Wafid AN, Zhang F (2010) Tandikek and Malalak flowslides triggered by 2009.9.30 M7.6 Sumatra earthquake during rainfall in Indonesia, Geoscience Report. Shimane Univ 29:1-10

Wu P, Hara M, Hamada JI, Yamanaka MD, Kimura F (2009) Why a large amount of rain falls over the sea in the vicinity of western Sumatra Island during nighttime. J Appl Meteorol Clim 48:1345-1361

Yamazaki F, Towhata I, Ishihara K (1985) Numerical model for liquefaction problem under multi-directional shearing on horizontal plane, Proceeding of Fifth International Conference on Numerical Methods in Geomechanics. 1-5 April 1985, Nagoya, Japan. p 399

Žlender B, Lenart S (2005) Cyclic liquefaction potential of lacustrine carbonate silt from Julian Alps. Acta Geotechnica Slovenica 2005(1):23-31

\section{doi:10.1186/s40677-014-0004-3}

Cite this article as: Faris and Fawu: Investigation of the initiation mechanism of an earthquake- induced landslide during rainfall: a case study of the Tandikat landslide, West Sumatra, Indonesia. Geoenvironmental Disasters 2014 1:4

\section{Submit your manuscript to a SpringerOpen ${ }^{\odot}$ journal and benefit from:}

- Convenient online submission

- Rigorous peer review

- Immediate publication on acceptance

- Open access: articles freely available online

- High visibility within the field

- Retaining the copyright to your article

Submit your next manuscript at $\gg$ springeropen.com 